Didáctica Geográfica nº 21, 2020,pp. 41-74

DOI: https://doi.org/10.21138/DG.519

ISSN electrónico: 2174-6451

\title{
LAS CONCEPCIONES SOBRE EL PAISAJE EN LA FORMA- CIÓN INICIAL DEL PROFESORADO
}

\author{
CONCEPTIONS ABOUT LANDSCAPE IN INITIAL TEACHER TRAINING
}

\section{LES CONCEPTIONS DU PAYSAGE DANS LA FORMATION INITIALE DES ENSEIGNANTS}

María Rosa Mateo Girona

Centro Universitario Villanueva

rmateogirona@gmail.com

Recibido: 29/05/2020

Aceptado 09/09/2020

\section{RESUMEN:}

El presente trabajo aborda una investigación sobre educación en el paisaje, la cual se ha desarrollado ampliamente a partir del Convenio de Paisaje (2000). Se presenta un estudio de caso, cuyo objetivo ha sido analizar las concepciones sobre el paisaje del alumnado de los Grados de Educación Primaria e Infantil y del Máster Universitario de Formación del Profesorado. Para ello, se ha realizado una prueba inicial en la que el alumnado ha trabajado sobre sus espacios vitales. El análisis se basa en la categorización de los elementos bióticos, abióticos y antrópicos, de esos paisajes. Algunos de los resultados evidencian que los alumnos identifican los paisajes desde su experiencia, y utilizan un vocabulario no especializado del ámbito geográfico; no relacionan, por tanto, esa realidad vivida con los contenidos académicos aprendidos. 


\section{Palabras clave:}

Didáctica de la Geografía; formación inicial del profesorado; educación en el paisaje; concepciones del alumnado; enfoque global y sistémico.

\section{Abstract:}

The present work deals with an investigation on education in the landscape, which has been developed extensively from the Landscape Convention (2000). A case study is presented, the objective of which is to analyze the conceptions of the landscape of the students of the Degrees of Primary and Infant Education and of the University Master's Degree in Teacher Training. For this, an initial test has been carried out in which the students have worked on their vital spaces. The analysis is based on the categorization of the biotic, abiotic and anthropic elements of these landscapes. Some of the results show that the students identify the landscapes from their experience, and use an unspecialized vocabulary from the geographical area; therefore, they do not relate this lived reality with the learned academic contents.

\section{KEYWORDS:}

Didactics of Geography, initial teacher training, landscape education, student conceptions, global and systemic approach.

\section{RÉSUMÉ:}

Dans le travail présent une recherche a été abordée sur l'éducation dans le cadre du paysage, largement développé à partir de la Convention du paysage (2000). Une étude de cas est présentée, dont l'objectif c'est d'analyser les conceptions sur le paysage des élèves des Grades Universitaires de Formation en enseignement primaire et préscolaire et du Master en formation d'enseignants. Pour cela, un premier test a été réalisé dans lequel les étudiants ont travaillé sur leurs espaces vitaux. L'analyse est basée sur la catégorisation des éléments biotiques, abiotiques et anthropiques de ces paysages. Quelques résultats montrent que les élèves identifient les paysages à partir de leur expérience et utilisent un vocabulaire non spécialisé du domaine géographique ; par conséquent, ils ne font pas le lien entre cette réalité vécue et le contenu académique appris.

\section{Mots-Clés:}

Didactique de la géographie; formation initiale des enseignants; éducation au paysage ; conceptions des étudiants; approche globale et systémique. 


\section{LA INVESTIGACIÓN SOBRE LA EDUCACIÓN EN EL PAISAJE DESDE LA DIDÁCTICA DE LA GEOGRAFÍA}

El Convenio Europeo del Paisaje (2000) ha reforzado el estudio del paisaje en la Geografía como contenido curricular de carácter innovador. Además, se contempla como el eje de una adecuada educación socio-ambiental. La formación inicial del profesorado es clave para la integración de estos aspectos en la educación formal.

La Geografía y el paisaje nacen al mismo tiempo como ciencia. Según Crespo (2017, p. 35) «El concepto de paisaje, como objeto de estudio de la Geografía, se perfila al tiempo que la misma ciencia geográfica comienza a adquirir su corpus científico». Sin embargo, desde el ámbito de la enseñanza de la Geografía apenas se está iniciando la investigación en didáctica del paisaje.

En el portal bibliográfico Dialnet, una búsqueda con las voces «didáctica del paisaje» y «geografía» evidencia que, en los últimos 24 años, se han defendido doce tesis doctorales realizadas desde las áreas de geografía y/o educación (Tabla 1). Se encuentra, además, una tesis realizada desde la lingüística y la educación aplicadas a la descripción geográfica (Mateo, 2016). Diez de estas tesis sobre didáctica de la geografía se presentan en la última década. Sólo dos se defienden antes del 2000, y son investigaciones realizadas en la universidad de Barcelona (1996) y en la de Castilla-La Mancha (1999). En estas dos universidades se han defendido más de la mitad de las tesis realizadas en estos años de esta temática, lo que indica el interés por profundizar en esta línea de investigación.

\begin{tabular}{|c|c|c|c|c|c|}
\hline & Autor & Año & Universidad & Director/es & Título \\
\hline 1 & $\begin{array}{l}\text { Pena i Vila, } \\
\text { Rosalina }\end{array}$ & 1996 & U. Barcelona & $\begin{array}{l}\text { Gómez Ortiz, } \\
\text { Antonio }\end{array}$ & $\begin{array}{l}\text { La geografía y la educación } \\
\text { ambiental. El estudio del } \\
\text { paisaje en el marco de la } \\
\text { enseñanza obligatoria }\end{array}$ \\
\hline 2 & $\begin{array}{l}\text { Sánchez López, } \\
\text { Lorenzo }\end{array}$ & 1999 & UCLM & $\begin{array}{l}\text { González } \\
\text { Cárdenas, } \\
\text { Elena }\end{array}$ & $\begin{array}{l}\text { Los cambios de paisaje en } \\
\text { Tomelloso. Estudio de la } \\
\text { geografía histórica de un } \\
\text { territorio como estrategia } \\
\text { didáctica }\end{array}$ \\
\hline 3 & $\begin{array}{l}\text { Granados } \\
\text { Sánchez, Jesús }\end{array}$ & 2010 & UAB & $\begin{array}{l}\text { Saurí i Pujol, } \\
\text { David } \\
\text { Casas Vilalta, } \\
\text { Montserrat }\end{array}$ & $\begin{array}{l}\text { L'educació per la sostenibilitat } \\
\text { a l'ensenyament de la } \\
\text { geografia: un estudi de cas }\end{array}$ \\
\hline
\end{tabular}




\begin{tabular}{|c|c|c|c|c|c|}
\hline & Autor & Año & Universidad & Director/es & Título \\
\hline 4 & $\begin{array}{l}\text { Serrano de la } \\
\text { Cruz Santos- } \\
\text { Olmo, Manuel } \\
\text { A. }\end{array}$ & 2013 & UCLM & $\begin{array}{l}\text { García } \\
\text { Rayego, José } \\
\text { Luis }\end{array}$ & $\begin{array}{l}\text { Análisis geográfico de los } \\
\text { paisajes del Campo de Montiel } \\
\text { Noroccidental (Ciudad } \\
\text { Real-Albacete): tipología, } \\
\text { dinámicas y valoración }\end{array}$ \\
\hline 5 & $\begin{array}{l}\text { Bianchi } \\
\text { Parraguez, } \\
\text { Roser M. }\end{array}$ & 2015 & U. Barcelona & $\begin{array}{l}\text { Gómez Ortiz, } \\
\text { Antonio }\end{array}$ & $\begin{array}{l}\text { El paisaje integrado, elemento } \\
\text { central de acción didáctica en } \\
\text { la enseñanza de la geografía. } \\
\text { El caso de Chile }\end{array}$ \\
\hline 6 & $\begin{array}{l}\text { Escobar Lahoz, } \\
\text { Estela }\end{array}$ & 2016 & UCLM & $\begin{array}{l}\text { González } \\
\text { Cárdenas, } \\
\text { Elena } \\
\text { Dóniz Páez, } \\
\text { Francisco } \\
\text { Javier }\end{array}$ & $\begin{array}{l}\text { Aprovechamiento de } \\
\text { los recursos volcánicos. } \\
\text { Mediterráneo central (Italia } \\
\text { peninsular), mediterráneo } \\
\text { occidental (Campo de } \\
\text { Calatrava) y entorno atlántico } \\
\text { (Islas Canarias) }\end{array}$ \\
\hline 7 & $\begin{array}{l}\text { Moreno } \\
\text { Nevado, } \\
\text { Margarita }\end{array}$ & 2016 & UCLM & $\begin{array}{l}\text { González } \\
\text { Cárdenas, } \\
\text { Elena } \\
\text { Becerra } \\
\text { Ramírez, R. }\end{array}$ & $\begin{array}{l}\text { El paisaje del río Ojailén. } \\
\text { Aplicaciones didácticas de } \\
\text { geografía para alumnos de } \\
\text { educación secundaria }\end{array}$ \\
\hline 8 & $\begin{array}{l}\text { Morón Monge, } \\
\text { M. del Carmen }\end{array}$ & 2016 & U. Huelva & $\begin{array}{l}\text { Estepa } \\
\text { Giménez, } \\
\text { Jesús } \\
\text { Doctor } \\
\text { Cabrera, } \\
\text { Alfonso }\end{array}$ & $\begin{array}{l}\text { El paisaje en la Enseñanza } \\
\text { Secundaria Obligatoria: } \\
\text { análisis de libros de texto y del } \\
\text { currículo oficial, el abordaje } \\
\text { patrimonial }\end{array}$ \\
\hline 9 & $\begin{array}{l}\text { Català } \\
\text { Marticella, } \\
\text { Rosa }\end{array}$ & 2017 & U. Barcelona & $\begin{array}{l}\text { Tort i Donada, } \\
\text { Joan }\end{array}$ & $\begin{array}{l}\text { La geografía como narración } \\
\text { descriptiva y como pedagogía } \\
\text { del mundo. La literatura } \\
\text { paisajística de Josep Pla como } \\
\text { caso de estudio }\end{array}$ \\
\hline 10 & $\begin{array}{l}\text { Coello } \\
\text { Hinojosa, } \\
\text { Flavio Enrique }\end{array}$ & 2017 & $\begin{array}{l}\text { U. Illes } \\
\text { Balears }\end{array}$ & $\begin{array}{l}\text { Seguí Llinàs, } \\
\text { Miquel }\end{array}$ & $\begin{array}{l}\text { Planificación territorial } \\
\text { de espacios rurales para } \\
\text { la utilización del turismo } \\
\text { como herramienta para la } \\
\text { conservación de la riqueza } \\
\text { natural y patrimonial de éstos }\end{array}$ \\
\hline
\end{tabular}




\begin{tabular}{|c|c|c|c|c|c|}
\hline & Autor & Año & Universidad & Director/es & Título \\
\hline 11 & $\begin{array}{l}\text { Crespo } \\
\text { Castellanos, } \\
\text { José Manuel }\end{array}$ & 2017 & $\mathrm{UCM}$ & $\begin{array}{l}\text { Marrón Gaite, } \\
\text { M}^{\mathrm{a}} \text { Jesús }\end{array}$ & $\begin{array}{l}\text { La educación en paisaje } \\
\text { en el Grado de Maestro de } \\
\text { Educación Primaria: propuesta } \\
\text { de un modelo didáctico }\end{array}$ \\
\hline 12 & $\begin{array}{l}\text { Casas Jericó, } \\
\text { María }\end{array}$ & 2018 & U. Navarra & $\begin{array}{l}\text { Puig Baguer, } \\
\text { Jordi } \\
\text { Erneta } \\
\text { Altarriba, } \\
\text { Luis }\end{array}$ & $\begin{array}{l}\text { El paisaje en educación } \\
\text { secundaria obligatoria: del } \\
\text { currículo y los libros de texto } \\
\text { al desarrollo de propuestas } \\
\text { didácticas }\end{array}$ \\
\hline
\end{tabular}

TABLA 1. Tesis doctorales sobre didáctica del paisaje y geografía (1996-2018). Fuente: Dialnet. Elaboración propia.

De igual modo, se han revisado los artículos publicados en la revista Didáctica Geográfica (en su segunda época, desde 1996 hasta el año 2019) y las comunicaciones incluidas en las actas de los congresos organizados por el grupo de trabajo de Didáctica de la Geografía de la AGE (los celebrados desde 1988 hasta 2019). Los trabajos se han seleccionado teniendo en cuenta la palabra clave: paisaje. Todos ellos se han incluido en tablas dinámicas a partir de las cuales se realizan las búsquedas correspondientes.

Entre los artículos localizados, la revista Didáctica Geográfica presenta veinte. En los congresos del grupo de Didáctica de la Geografía de la AGE son 152 las comunicaciones y ponencias presentadas. El total es de 172 trabajos sobre esta temática a lo largo de los 31 años. El promedio de artículos aparecidos es de siete trabajos al año, aunque se constata que casi un $60 \%$ de los mismos se han presentado en los últimos seis años.

En la Figura 1 aparece la evolución de esta producción bibliográfica. Los años 1996, 2014, 2018 y 2019 se pueden considerar como hitos en la aportación de trabajos sobre didáctica del paisaje. Tienen en común que avanzan en el estudio de esta didáctica desde una doble dimensión: contenidos curriculares innovadores e integración de la educación socioambiental.

En 1996, María Jesús Marrón Gaite, coordinadora de las III Jornadas de Didáctica de la Geografía, plantea uno de los grandes temas abordados en la propia presentación del libro de Actas: «¿Qué sentido procede atribuir al concepto de paisaje como núcleo vertebrador de los conocimientos geográficos?» Veinte comunicaciones defendieron la idea de que el paisaje debe ser el núcleo que vertebre los contenidos geográficos físicos y humanos de la geografía escolar, especialmente Gómez Ortiz (1996) afirma la ciencia del paisaje, recuerda la tradición en la didáctica del mismo de la Institución Libre de Enseñanza a través de las excursiones pedagógicas, y defiende la presencia de estos contenidos en el 
diseño curricular, aportando un modelo para trabajar el paisaje de montaña con sugerencias didácticas. Sólo una comunicación abordaba el estudio del paisaje desde un enfoque diferente, basado en los procedimientos, en el saber hacer más que en el saber.

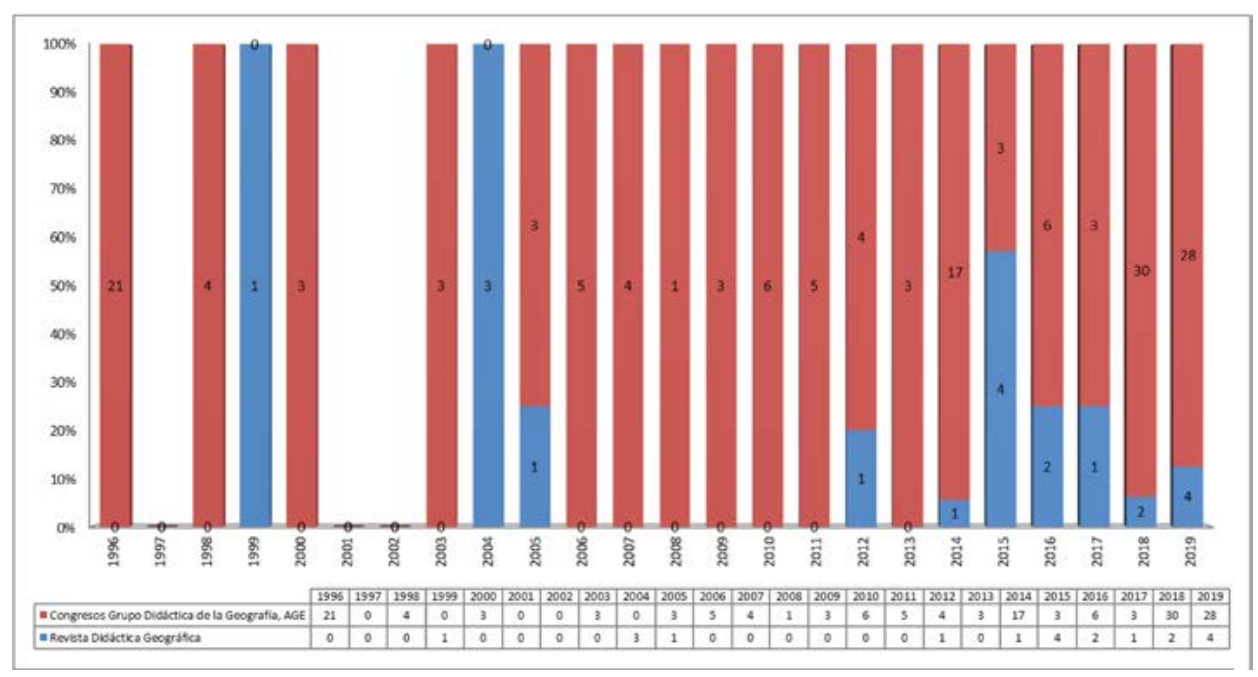

FIgURA 1. Evolución de los trabajos bibliográficos sobre paisaje desde la didáctica de la geografía (1988-2019). Fuente: elaboración propia.

En 2014, se presentan diecisiete comunicaciones al congreso del grupo de Didáctica de la Geografía de la AGE Nuevas perspectivas conceptuales y metodológicas para la educación geográfica, coordinado por Martínez y Tonda. Estos trabajos se presentan en tres de las cuatro líneas propuestas: la construcción del conocimiento desde las ideas previas, la normativa y el desarrollo curricular en el nuevo contexto de la LOMCE; y, finalmente, la innovación y práctica en la enseñanza de la geografía. Los enfoques de la didáctica del paisaje se amplían con la primera de las líneas y se profundiza en algunos aspectos de lo que ya se trabajaban con la segunda y tercera.

Para terminar, destacan los congresos celebrados en los últimos años, 2018 y 2019. Con 30 y 28 trabajos presentados en cada uno de ellos, suponen el 33,7\% de los trabajos de las últimas décadas. El lema del congreso de 2018 era: El paisaje, múltiples miradas sobre el aprendizaje de la geografía centra el tema del paisaje. Martínez de Pisón (2018) señalaba en Paisajes pedagógicos, la relación entre medio físico y humanidad, subrayaba la mirada que descubre el territorio como paisaje para ir más allá de las apariencias y la mirada del alumno como estímulo para la mirada del maestro. Como ocurrió en 1996, uno de los tres ejes temáticos se enfocaba directamente al paisaje como centro de interés 
educativo de enfoque transdisciplinar de la geografía. Se presentaron 30 comunicaciones que subrayaban ese enfoque transdisciplinar de la geografía y de su didáctica. Las sedes del IX Congreso Ibérico de didáctica de la Geografía fueron Santiago de Compostela y Lugo, celebrado en 2019, sobre La reconfiguración del medio rural en la sociedad de la información. Nuevos desafíos en la educación geográfica. Aunque no se citaba explícitamente el paisaje rural en ninguna de las líneas temáticas, sí aparecían expresiones como "medio rural" o "área rural"; finalmente, las investigaciones que incluyen entre sus palabras claves la de "paisaje" son 28. Aparece sin calificar en siete ocasiones, y se completa con el adjetivo "rural" en catorce ocasiones, como paisaje cultural se repite tres veces, y también encontramos paisaje "urbano", "natural", "singular" o "agrario". Se puede concluir que la investigación en didáctica del paisaje está comenzando ahora.

Para este trabajo, además de las comunicaciones ya comentadas en conjunto, resultaron inspiradoras las investigaciones llevadas a cabo por Gómez (1996), Liceras $(1996,2003)$ y Crespo (2017), desde el punto de vista teórico; y de este último y Adrados (1998) desde la aplicación al aula universitaria y de primaria respectivamente.

La concepción del paisaje desde un enfoque global y sistémico se define por Gómez como «una porción de la superficie terrestre (epigeosfera) delimitada en el tiempo y caracterizada por la interactuación de distintos subsistemas (abiótico, biótico y antrópico) que, actuando de forma interconexionada, se modifican y evolucionan en bloque» (1996, p. 197). Así pues, los elementos del paisaje se han categorizado como abióticos, bióticos y antrópicos (Tabla 2). El primer nivel consta de estos tres elementos y el segundo nivel incluye cuatro subcategorías para los abióticos, tres para los bióticos y cuatro para los antrópicos (adaptado de Liceras, 2003). Además, se ha tenido en cuenta la clasificación de Adrados (1998) para incluir un tercer nivel con 54 elementos.

\begin{tabular}{|c|c|c|c|c|c|c|c|c|c|c|c|c|c|c|c|c|c|c|c|c|c|c|c|c|c|}
\hline \multicolumn{16}{|c|}{ ELEMENTOS ABIÓTICOS } & \multicolumn{10}{|c|}{ ELEMENTOS BIÓTICOS } \\
\hline \multicolumn{5}{|c|}{ Relieve } & \multicolumn{5}{|c|}{ Hidrografía } & \multicolumn{3}{|c|}{ Atmósfera } & \multicolumn{3}{|c|}{ Astros } & \multicolumn{6}{|c|}{ Vegetación } & \multicolumn{2}{|c|}{ Animales } & \multicolumn{2}{|c|}{$\begin{array}{c}\text { Presencia } \\
\text { Humana }\end{array}$} \\
\hline 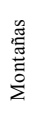 & 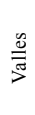 & $\begin{array}{l}\text { 苞 } \\
\text { 奇 }\end{array}$ & $\frac{\mathscr{g}}{\underline{\pi}}$ & $\stackrel{\text { In }}{0}$ & $\frac{a}{2}$ & 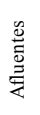 & $\stackrel{\substack{\mathscr{m} \\
\Sigma}}{\Sigma}$ & $\begin{array}{l}\text { 品 } \\
\text { 胥 } \\
\text { J }\end{array}$ & 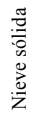 & 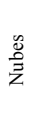 & 总 & 茎 & $\overline{\dot{D}}$ & $\stackrel{\Xi}{\Xi}$ & 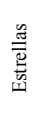 & $\begin{array}{l}\frac{0}{0} \\
\frac{0}{z}\end{array}$ & 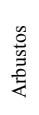 & 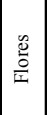 & 造 & 栉 & 点 & 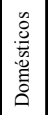 & 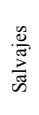 & \begin{tabular}{|l|}
$\stackrel{n}{2}$ \\
$\stackrel{9}{z}$
\end{tabular} & $\frac{n}{\frac{0}{3}}$ \\
\hline
\end{tabular}

\begin{tabular}{|c|c|c|c|c|c|c|c|c|c|c|c|c|c|c|c|c|c|c|c|c|c|c|c|c|c|}
\hline \multicolumn{26}{|c|}{ ELEMENTOS ANTRÓPICOS } \\
\hline \multicolumn{11}{|c|}{ Edificaciones } & \multicolumn{7}{|c|}{ Vías de comunicación } & \multicolumn{7}{|c|}{ Medios de transporte } & $\begin{array}{c}\text { Utensilios } \\
\text { humanos }\end{array}$ \\
\hline 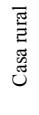 & 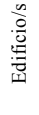 & 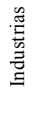 & 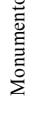 & 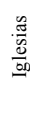 & $\frac{0}{\frac{0}{0}}$ & 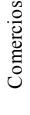 & 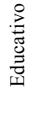 & 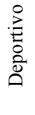 & 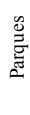 & 온 & 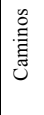 & 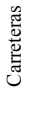 & $\frac{\mathscr{\Xi}}{\bar{J}}$ & $\begin{array}{l}\text { 胥 } \\
\text { 永 }\end{array}$ & 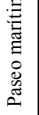 & 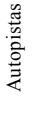 & 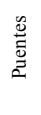 & $\frac{\frac{\pi}{0}}{\frac{0}{0}} \frac{\pi}{\frac{0}{0}}$ & $\stackrel{n}{\bar{m}}$ & $\stackrel{\mathbb{E}}{\mathrm{O}}^{0}$ & $\begin{array}{l}\frac{\pi}{0} \\
0 \\
0\end{array}$ & $\frac{\sqrt[0]{0}}{\frac{0}{4}}$ & 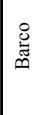 & $\stackrel{\infty}{0}$ & $\stackrel{\Xi}{0}$ \\
\hline
\end{tabular}

TABla 2. Categorías de elementos para caracterizar el paisaje. Fuente: elaboración propia sobre Adrados (1998). 
Estas categorías han servido para analizar las representaciones del alumnado acerca del paisaje, las cuáles se han obtenido de sus dibujos (Adrados, 1998) y de sus descripciones.

Por último, las descripciones se han analizado siguiendo, en parte, una clasificación de las estrategias descriptivas escritas (Mateo, 2016) que aparecen en la Tabla 3: identifica, ordena y relaciona.

\begin{tabular}{|c|c|c|c|c|c|}
\hline Destrezas & Buscar & Elaborar & Razonar & Comunicar & Revisar \\
\hline $\begin{array}{l}\text { Estrategias } \\
\text { descriptivas }\end{array}$ & $\begin{array}{l}\text { 1. Observar } \\
\text { 2. Identificar } \\
\text { 3. Localizar, } \\
\text { situar } \\
\text { 4. Recordar } \\
\text { 5. Investigar }\end{array}$ & $\begin{array}{l}\text { 1. Seleccionar, } \\
\text { elegir } \\
\text { 2. Ordenar } \\
\text { 3. Clasificar, } \\
\text { jerarquizar } \\
\text { 4. Enumerar } \\
\text { 5. Organizar }\end{array}$ & $\begin{array}{l}\text { 1. Relacionar, } \\
\text { comparar } \\
\text { 2. Calcular, } \\
\text { resolver } \\
\text { 3. Comprobar, } \\
\text { verificar } \\
\text { 4. Analizar } \\
\text { 5. Aplicar }\end{array}$ & $\begin{array}{l}\text { 1. Concretar } \\
\text { 2. Ejemplificar } \\
\text { 3. Resumir, } \\
\text { sintetizar } \\
\text { 4. Explicar } \\
\text { 5. Crear }\end{array}$ & $\begin{array}{l}\text { 1. Copiar, } \\
\text { repetir } \\
\text { 2. Rellenar, } \\
\text { completar } \\
\text { 3. Memorizar } \\
\text { 4. Verificar, } \\
\text { comprobar } \\
\text { 5. Sustituir, } \\
\text { reelaborar }\end{array}$ \\
\hline $\begin{array}{l}\text { Estrategias } \\
\text { descriptivas } \\
\text { escritas }\end{array}$ & Identificar & Ordenar & Relacionar & Concretar & Reelaborar \\
\hline
\end{tabular}

TABla 3. Propuesta de clasificación de las estrategias descriptivas según Mateo. Fuente: Mateo, M.T. (2016).

Los descriptores utilizados para clasificar cada una de esas estrategias en las descripciones de los alumnos son:

- Identificar: nombra los elementos del paisaje que describe (ej. topónimos), los sitúa desde punto de vista administrativo o sus límites o puntos cardinales.

- Ordenar: describe los elementos físicos (relieve, clima, hidrografía, vegetación, fauna) y humanos (población, urbanización, transportes y economía) con una estructura razonada.

- Relacionar: establece relaciones de causa-efecto entre los elementos físicos y humanos de las distintas categorías.

\section{OBJETIVOS Y METODOLOGÍA}

El objetivo de este estudio es conocer qué concepciones sobre el paisaje tienen los estudiantes que cursan el grado de educación infantil (en adelante GEI), el grado de educación primaria (en adelante GEP) y el master universitario de formación de profesorado de secundaria (en adelante MFPS), que reciben su formación inicial en las aulas universitarias y serán los futuros profesores de los distintos niveles. 
Los objetivos secundarios son: reflexionar sobre los motivos que les inducen a seleccionar unos paisajes sobre otros, detectar el grado de coherencia entre lo que dibujan y lo que describen, analizar las estrategias descriptivas que utilizan y conocer el vocabulario que utilizan a la hora de describir el paisaje.

La muestra de tres cursos académicos suma 182 estudiantes, distribuidos por sexo y titulaciones según aparece en la Tabla 4. En el curso 2017/2018 se validó la prueba con 18 sujetos de GEI y GEP. En el curso 2018/2019 se aplicó a 94 alumnos durante la primera semana del curso, en cada una de las titulaciones, con carácter voluntario (participaron el 88\% de los alumnos). Finalmente, en el curso 2019/2020 se aplicó a 70 alumnos en los mismos tiempos, cursos y carácter voluntario que en el curso anterior, y participaron el $75 \%$ de los alumnos.

\begin{tabular}{lrrrr}
\hline & Sexo & Grado EI & Grado EP & MFSP \\
\hline Varones & 37 & 1 & 13 & 23 \\
Mujeres & 145 & 26 & 98 & 21 \\
\hline Total & 182 & 27 & 111 & 44 \\
\hline
\end{tabular}

TABLA 4. Distribución por sexo y titulación de la muestra. Fuente: elaboración propia.

$\mathrm{El}$ instrumento para conocer estas ideas previas es una ficha en la que se plantea una práctica que tiene dos secuencias:

1. Realizar un eje cronológico con los paisajes en los que han nacido, vivido y/o visitado; los lugares y la motivación de sus viajes; por último, las experiencias positivas y negativas vividas en esos espacios.

2. Seleccionar, dibujar y describir (destacando los elementos que considere más importantes) el paisaje que más les guste.

El procesamiento de los datos se realiza en cuatro fases. En primer lugar, se clasifican los paisajes en los que han nacido, vivido o viajado los alumnos que realizan la práctica (desagregando los datos por provincias en el caso de los paisajes de España, y por países en los paisajes exteriores). También, se separan las motivaciones de esos viajes en dos tipos: los realizados por turismo, veraneo, etc. y los realizados por estudios, trabajo o cooperación.

En segundo lugar, se analizan los dibujos de los alumnos, por titulaciones, y se identifican los elementos que se corresponden con las categorías reflejadas en la Tabla 2. En el Anexo 1 se muestra un dibujo que incluye elementos de todas las categorías, mientras que en el Anexo 2 solo aparecen dibujados elementos abióticos (véase: mar y arena) y bióticos (véase: dos palmeras y tres aves). 
En tercer lugar, se analizan las descripciones escritas de los alumnos (por titulaciones) sobre los dibujos de sus paisajes de tres formas:

- se aplica las clasificaciones de Liceras (2003) y Crespo (2017) para valorar el enfoque global o no, aplicado por los alumnos.

- se sigue la misma clasificación de la Tabla 2, para comprobar el grado de coherencia entre lo que dibujan y lo que describen; así como el vocabulario geográfico que utilizaron los alumnos en las descripciones, como variable para comprobar su grado de especialización.

- se utiliza la clasificación de la Tabla 3, para conocer las estrategias descriptivas (Mateo, 2016) escritas que utilizan.

\section{RESULTADOS}

\subsection{Localización de los paisajes "vividos" por los alumnos}

El primer dato que se examina es el lugar de nacimiento de los estudiantes (Tabla 5).

\begin{tabular}{|c|c|c|c|c|c|c|}
\hline Comunidad Autónoma & Provincia & $\mathrm{n} \%$ prov. & n $/$ C.A. & $\%$ & País & n\%/País \\
\hline \multirow{3}{*}{ Andalucía } & Córdoba & 4 & \multirow{3}{*}{6} & \multirow{3}{*}{3,3} & Bélgica & 1 \\
\hline & Granada & 1 & & & Chequia & 1 \\
\hline & Sevilla & 1 & & & Inglaterra & 1 \\
\hline Aragón & Zaragoza & 2 & 2 & 1,1 & Italia & 1 \\
\hline Balears, Illes & Balears, Illes & 2 & 2 & 1,1 & Rumanía & 1 \\
\hline \multirow{2}{*}{ Canarias } & Palmas, Las & 2 & \multirow{2}{*}{4} & \multirow{2}{*}{2,2} & Rusia & 1 \\
\hline & Santa Cruz de Tenerife & 2 & & & Ucrania & 1 \\
\hline Cantabria & Cantabria & 1 & 1 & 0,5 & U.S.A. & 1 \\
\hline Castilla y León & Ávila & 2 & 2 & 1,1 & México & 2 \\
\hline \multirow{3}{*}{ Castilla - La Mancha } & Albacete & 1 & \multirow{3}{*}{4} & \multirow{3}{*}{2,2} & Cuba & 1 \\
\hline & Ciudad Real & 1 & & & El Salvador & 1 \\
\hline & Cuenca & 2 & & & Guatemala & 4 \\
\hline Cataluña & Barcelona & 1 & 1 & 0,5 & \begin{tabular}{|l|} 
Venezuela \\
\end{tabular} & 1 \\
\hline \multirow{3}{*}{ Comunitat Valenciana } & Alicante & 5 & \multirow{3}{*}{10} & \multirow{3}{*}{5,5} & Perú & 1 \\
\hline & Castellón & 1 & & & India & 1 \\
\hline & Valencia & 4 & & & & \\
\hline Extremadura & Badajoz & 3 & 3 & 1,6 & & \\
\hline \multirow{2}{*}{ Galicia } & Coruña, A & 1 & \multirow{2}{*}{2} & \multirow{2}{*}{1,1} & & \\
\hline & Pontevedra & 1 & & & & \\
\hline Madrid, Comunidad de & Madrid & 120 & 120 & 65,9 & & \\
\hline Murcia, Región de & Murcia & 4 & 4 & 2,2 & & \\
\hline Navarra, Comunidad Foral de & Navarra & 1 & 1 & 0,5 & & \\
\hline \multirow[t]{3}{*}{ Vasco, País } & Vizcaya & 1 & 1 & 0,5 & & \\
\hline & \multicolumn{2}{|l|}{ TOTAL ESPAÑA } & 163 & 89,6 & & \\
\hline & \multicolumn{2}{|l|}{ TOTAL EXTRANJERO } & 19 & 10,4 & & \\
\hline
\end{tabular}

TABLA 5. Paisajes en los que han nacido (según provincia, autonomía para los nacidos en España o país para los nacidos en el extranjero). Fuente: elaboración propia. 
Casi el 90\% de los alumnos han nacido en España, el 10\% restante en diferentes países europeos, americanos y asiático. Entre los españoles, el 66\% son nacidos en Madrid y el 34\% restante se reparten entre 22 provincias. Por otra parte, entre los de origen nacional, el 84\% proceden de paisajes de interior y el $16 \%$ de paisajes de costa. También entre los estudiantes españoles, se constata que el $95 \%$ nace en paisajes urbanos y el 5\% en rurales. Así pues, el perfil del origen de nuestra muestra sería estudiante nacional de origen urbano y de interior.

En segundo lugar, se analizan los paisajes visitados por los alumnos. Se registran un total de 1436 paisajes visitados, lo que arroja una media de 7,8 paisajes por alumno de forma global. Si se diferencia por paisajes españoles o foráneos, se observa que la media en el interior de España es de 4,1, y para el extranjero es de 3,8. Se agrupan los paisajes según continente para no alargar innecesariamente el texto (separando España). En las Figuras 2 y 3 se muestran la localización de paisajes visitados por continentes y los paisajes seleccionados por los estudiantes como los preferidos, respectivamente. En la Tabla 6 se concretan éstos últimos por provincias, en el caso de España, y por países para el extranjero.

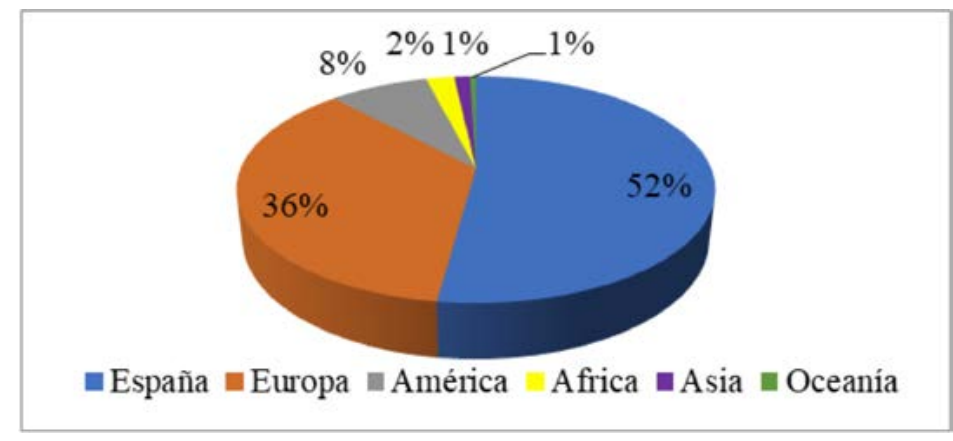

FiguRA 2. Localización de paisajes visitados según continentes (\%). Fuente elaboración propia.

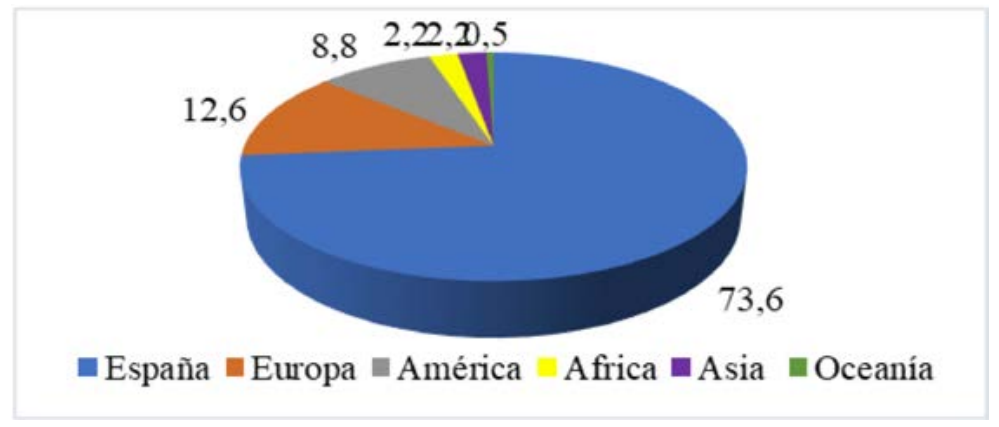

FIGURA 3. Paisajes seleccionados por los estudiantes como los preferidos (\%). Fuente: elaboración propia. 


\begin{tabular}{|c|c|c|c|c|c|c|}
\hline Comunidad Autónoma & Provincia & $\mathrm{n}^{\mathrm{o} / \mathrm{prov} \text {. }}$ & $n \%$ C.A. & $\%$ & País & n\%país \\
\hline \multirow{5}{*}{ Andalucía } & Cádiz & 6 & \multirow{5}{*}{15} & \multirow{5}{*}{11,2} & Alemanía & 1 \\
\hline & Córdoba & 2 & & & Austria & 1 \\
\hline & Granada & 4 & & & \begin{tabular}{|l} 
Bélgica \\
\end{tabular} & 1 \\
\hline & Jaén & 1 & & & Chequia & 1 \\
\hline & Sevilla & 2 & & & Finlandia & 1 \\
\hline \multirow{2}{*}{ Aragón } & Teruel & 1 & \multirow{2}{*}{2} & \multirow{2}{*}{1,5} & Francia & 3 \\
\hline & Zaragoza & 1 & & & Grecia & 3 \\
\hline Asturias, Principado de & Asturias & 8 & 8 & 0,7 & Holanda & 2 \\
\hline Balears, Illes & Balears, Illes & 6 & 6 & 4,5 & \begin{tabular}{|l|} 
Inglaterra \\
\end{tabular} & 1 \\
\hline \multirow{2}{*}{ Canarias } & Palmas, Las & 5 & \multirow{2}{*}{9} & \multirow{2}{*}{6,7} & Irlanda & 1 \\
\hline & Santa Cruz de Tenerife & 4 & & & Italia & 5 \\
\hline Cantabria & Cantabria & 10 & 10 & 7,5 & Portugal & 2 \\
\hline \multirow{7}{*}{ Castilla y León } & Ávila & 6 & \multirow{7}{*}{14} & \multirow{7}{*}{10,4} & \begin{tabular}{|l|} 
Suiza \\
\end{tabular} & 1 \\
\hline & \begin{tabular}{|l} 
León \\
\end{tabular} & 1 & & & E.E.U.U. & 2 \\
\hline & Palencia & 1 & & & México & 4 \\
\hline & Segovia & 2 & & & \begin{tabular}{|l|} 
Cuba \\
\end{tabular} & 2 \\
\hline & \begin{tabular}{|l} 
Soria \\
\end{tabular} & 1 & & & Argentina & 1 \\
\hline & \begin{tabular}{|l|} 
Valladolid \\
\end{tabular} & 1 & & & Ecuador & 1 \\
\hline & Zamora & 2 & & & Guatemala & 2 \\
\hline \multirow{4}{*}{ Castilla - La Mancha } & Albacete & 1 & \multirow{4}{*}{6} & \multirow{4}{*}{4,5} & Perú & 3 \\
\hline & \begin{tabular}{|l} 
Ciudad Real \\
\end{tabular} & 1 & & & Venezuela & 1 \\
\hline & Cuenca & 2 & & & Marruecos & 1 \\
\hline & Guadalajara & 2 & & & Kenia & 1 \\
\hline \multirow{3}{*}{ Comunitat Valenciana } & Alicante/Alacant & 7 & \multirow{3}{*}{12} & \multirow{3}{*}{9,0} & Uganda & 2 \\
\hline & Castellón/Castelló & 2 & & & Malasia & 1 \\
\hline & Valencia & 3 & & & Thailandia & 1 \\
\hline \multirow{2}{*}{ Extremadura } & Cáceres & 1 & \multirow{2}{*}{4} & \multirow{2}{*}{3,0} & \begin{tabular}{|l} 
Singapure \\
\end{tabular} & 1 \\
\hline & Badajoz & 3 & & & China & 1 \\
\hline \multirow{3}{*}{ Galicia } & Coruña, A & 5 & \multirow{3}{*}{13} & \multirow{3}{*}{1,1} & Australia & 1 \\
\hline & Ourense & 1 & & & & \\
\hline & Pontevedra & 7 & & & & \\
\hline Madrid, Comunidad de & Madrid & 26 & 26 & 19,4 & & \\
\hline Murcia, Región de & Murcia & 5 & 5 & 3,7 & & \\
\hline Navarra, Comunidad Foral de & Navarra & 3 & 3 & 2,2 & & \\
\hline \multirow[t]{3}{*}{ Vasco, País } & Álava & 1 & 1 & 0,7 & & \\
\hline & \multicolumn{2}{|l|}{ TOTAL ESPAÑA } & 134 & 73,6 & & \\
\hline & \multicolumn{2}{|l|}{ TOTAL EXTRANJERO } & 48 & 26,4 & & \\
\hline
\end{tabular}

TABLa 6. Paisajes escogidos (según provincia, autonomía para los de España o país para los de extranjeros). Fuente: elaboración propia.

El paisaje de nacimiento y el paisaje que más les gusta, coincide para el $28 \%$ de los alumnos, mientras que un $72 \%$ eligen como preferencia un paisaje distinto al de nacimiento. Si desglosamos estos datos por titulaciones (Figura 4) encontramos que los estudiantes de GEP y de MFPS diferencian más entre el paisaje de nacimiento y el 
paisaje preferido, mientras que en GEI el paisaje de nacimiento es el paisaje elegido por el $37 \%$ de los alumnos con una diferencia de 10 puntos sobre los anteriores.

Destaca el caso de los estudiantes de Madrid. De los 120 estudiantes que han nacido en esta región, sólo el 17\% dicen preferir Madrid como paisaje, mientras que el 83\% señalan otros paisajes. Estos mismos alumnos madrileños, el $27 \%$ prefiere los paisajes de países extranjeros, y el 73\% restante apuntan paisajes nacionales; el 53\% prefiere los paisajes litorales de España y el $47 \%$ paisajes del interior.
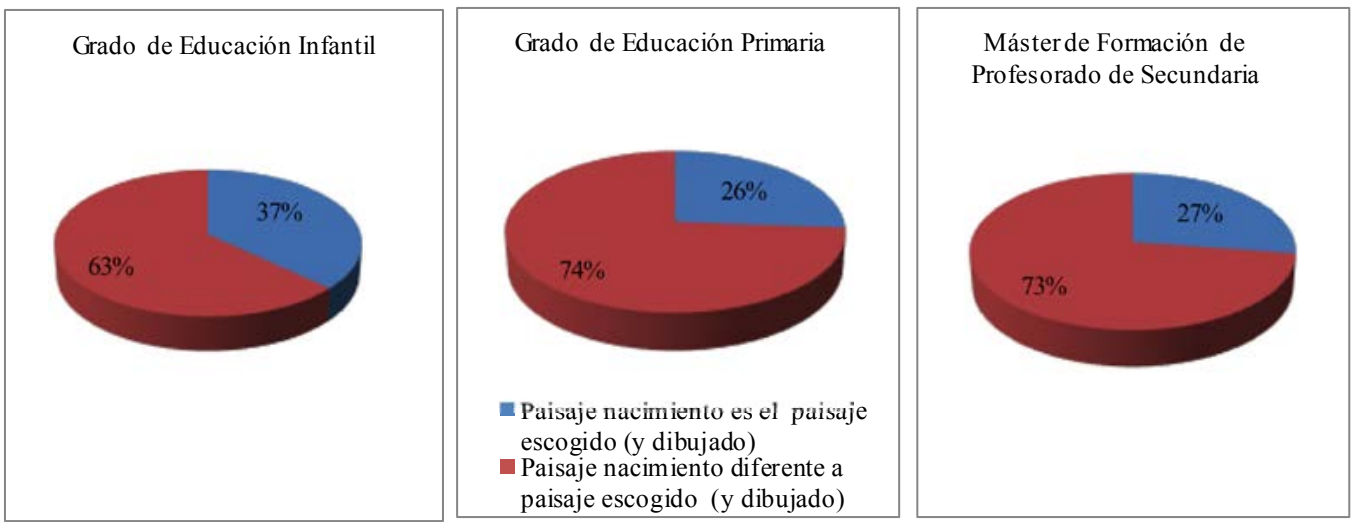

FIgURA 4. Relación entre el paisaje de nacimiento de los estudiantes según la titulación y el paisaje escogido (\%). Fuente: elaboración propia.

Por último, se retoma la división de paisajes extranjeros y nacionales vistos en Tabla 6 y Figura 3; profundizando en la diferencia, dentro de los nacionales, de paisajes costeros y de interior (Figura 5) según la titulación de los estudiantes.

Se observa que, para el conjunto de los estudiantes, el 54\% de los paisajes preferidos se sitúan en provincias costeras, mientras que el $46 \%$ serían paisajes de interior. Por titulaciones, los datos más significativos son los de los estudiantes de GEI que prefieren los paisajes de interior, mientras los de GEP eligen los de litoral. 


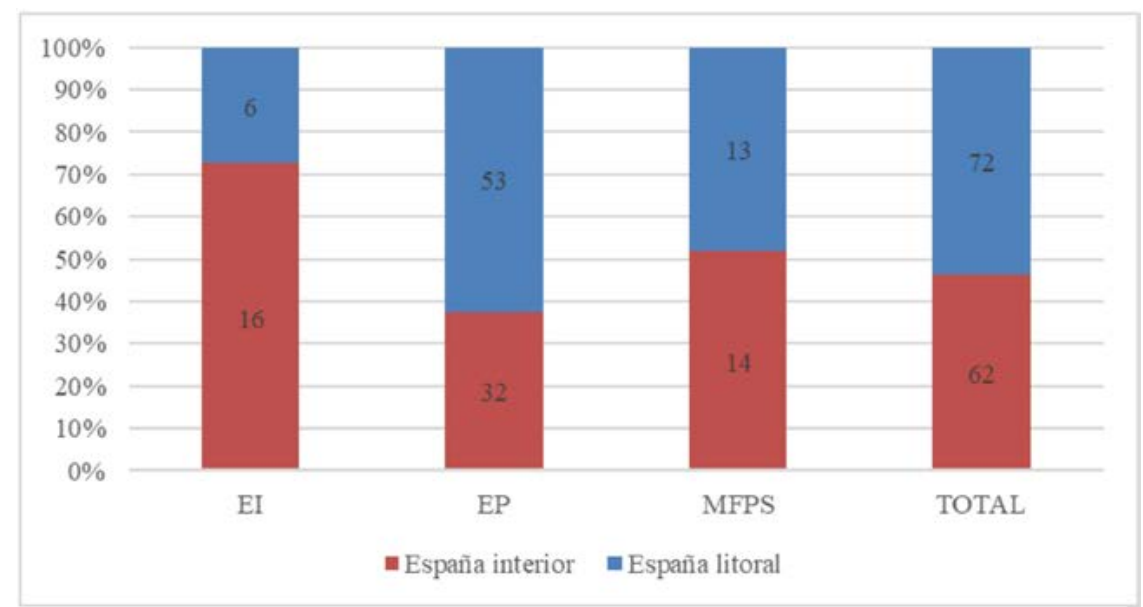

FIGURA 5. Paisajes preferidos por los estudiantes según la titulación y el tipo de paisaje (extranjero o nacional - costero/litoral-) (\%). Fuente: elaboración propia.

En la Figura 6 se analiza la división paisajes rurales o urbanos según la titulación de los estudiantes. Sólo los alumnos que cursan el GEI prefieren los espacios urbanos $(59 \%)$ frente a los rurales $(41 \%)$. En las otras dos titulaciones, se prefieren los rurales a los urbanos. De forma más rotunda entre los alumnos de MFPS que son un $77 \%$ los que eligen entornos rurales a $23 \%$ de urbanos. En GEP, los porcentajes varían con un $65 \%$ de estudiantes que apunta a espacio rurales y $35 \%$ a urbanos.

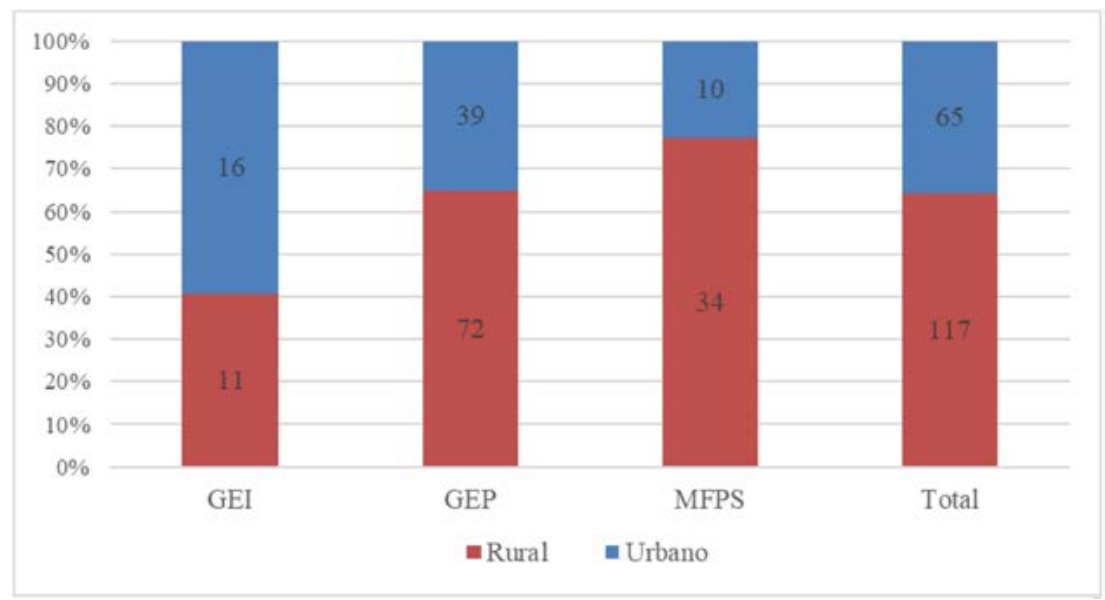

FiguRa 6. Paisajes preferidos por los estudiantes según la titulación y el tipo de paisaje (ruralurbano) (\%). Fuente: elaboración propia. 


\subsection{Paisajes dibujados por los alumnos}

De los 182 sujetos que participaron en estas pruebas, quince no realizaron el dibujo; el resto, 167 sí lo han hecho, lo que supone un 91,8\% de los alumnos. La Figura 7 refleja que los elementos que más dibujan los alumnos universitarios se encuentran dentro de la categoría de elementos abióticos (44\%), seguidos de los elementos antrópicos (32\%) y en último lugar, de los bióticos (24\%). En números absolutos, se han identificado 1033 elementos dibujados entre todas las categorías. Si desglosamos por titulaciones, observamos que los estudiantes del GEI subrayan los elementos antrópicos, después los abióticos y finalmente los bióticos. Los alumnos del GEP representan más los elementos abióticos y casi en la misma proporción los antrópicos y bióticos. Finalmente, en los dibujos de los alumnos de MFPS predominan claramente los elementos abióticos, seguidos de los antrópicos y, en menor grado, los bióticos.
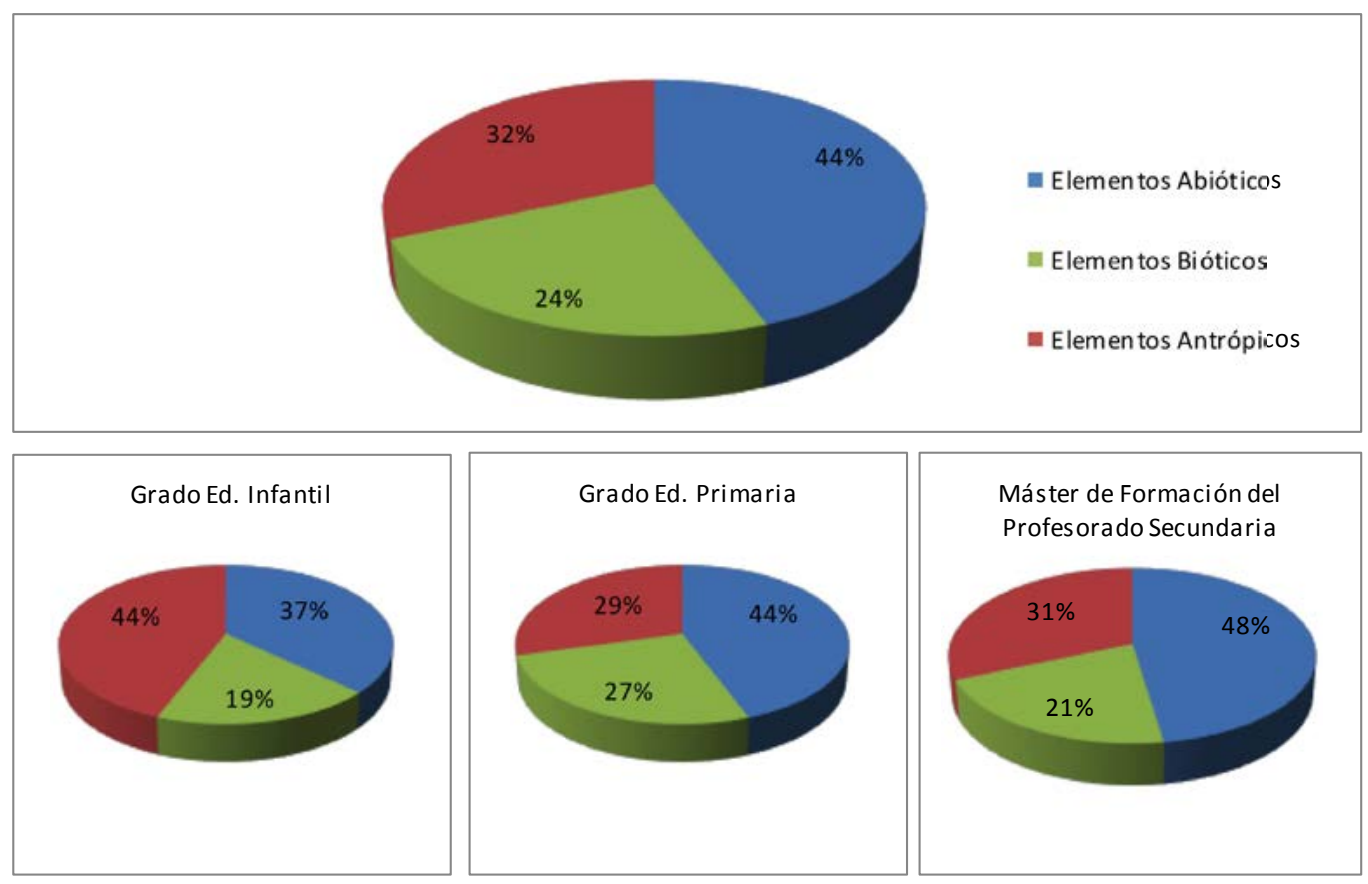

FIGURA 7. Distribución de los elementos abióticos, bióticos y antrópicos del paisaje dibujado, total y por titulaciones (\%). Fuente: elaboración propia.

En las Figuras 8, 9 y 10, se exponen los elementos dibujados por los alumnos clasificados en el segundo nivel. La Figura 8 muestra, entre los elementos abióticos, los más representados en el apartado de relieve han sido las montañas (69) y las llanuras 
(55), en el apartado «otros» el elemento dibujado era la playa, el acantilado, la cala, el páramo, etc. (44). En el apartado de hidrografía, los elementos que más se repiten son mares (64) y, a distancia, los ríos (36). En cuanto a la atmósfera son las nubes (35) y, finalmente en la categoría de los astros, el sol (44), relacionado este último con el clima caluroso de los paisajes elegidos. Los elementos como ríos, viento, humo o arco iris son representados (pocos en números absolutos) por los estudiantes de GEI. En casi todos los elementos, los estudiantes de GEP dibujan más del 50\% de los elementos abióticos, llegando al $80 \%$ de los que representan la lluvia. Finalmente, pocos alumnos del MFPS representan elementos como la afluentes, luna y estrellas, éstos dos últimos de forma exclusiva.

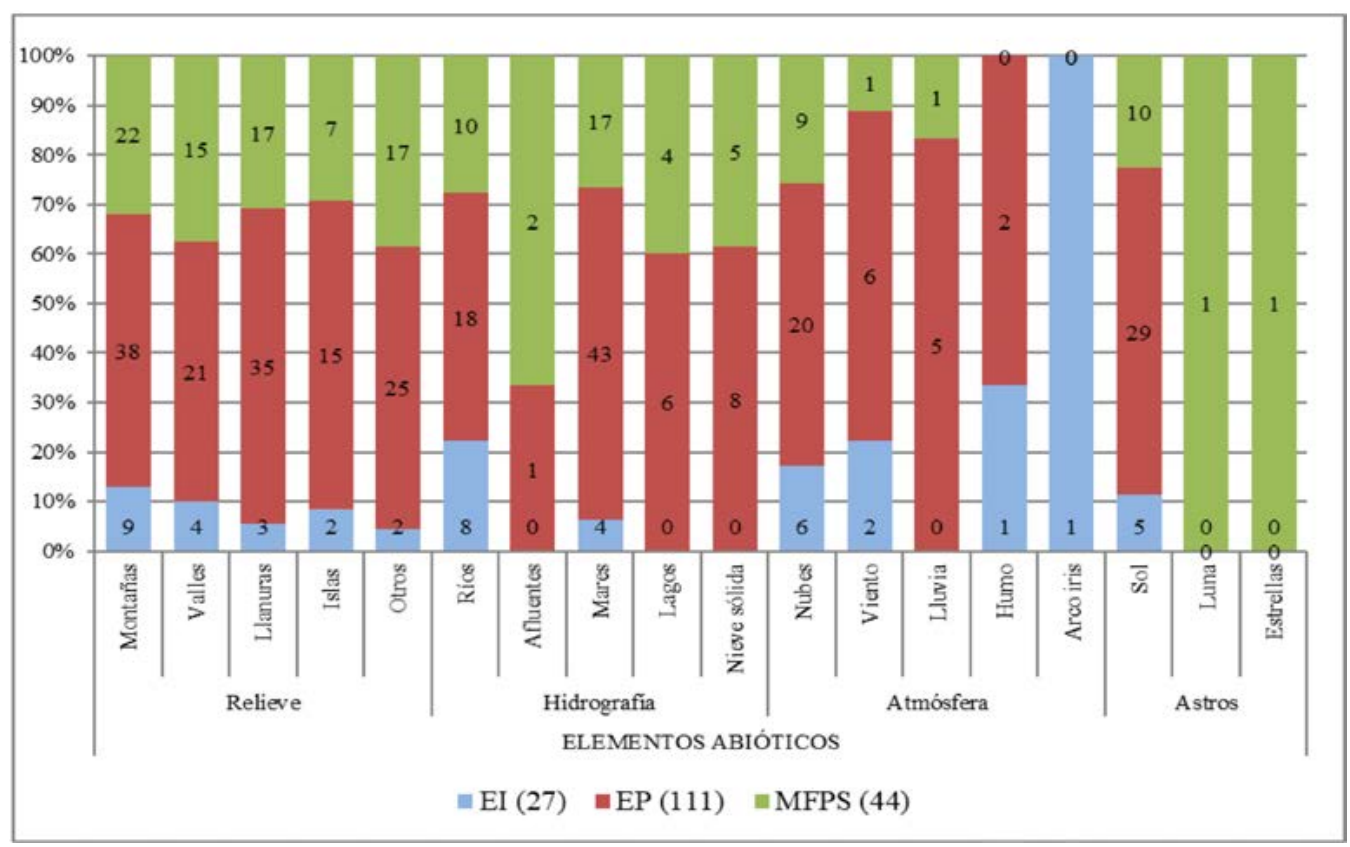

FiguRA 8. Distribución de los elementos abióticos según subcategorías y titulaciones. Fuente: elaboración propia

En la Figura 9, en la categoría vegetación, aparecen los árboles (82) como los elementos que más se repiten en los dibujos realizados, o los arbustos (45), los animales salvajes que han dibujado (30) son pájaros en zona de costa, y apenas hay presencia humana en los dibujos recogidos (20). Por titulaciones, llama la atención que son los alumnos del MFPS los que dibujan elementos de huertas: campos de cereales, viñas, 
etc. y éstos y los del GEI los que representan jardines. El resto de elementos bióticos son alumnos de GEP los que más los dibujan, especialmento la presencia humana: sólo niños y adultos.

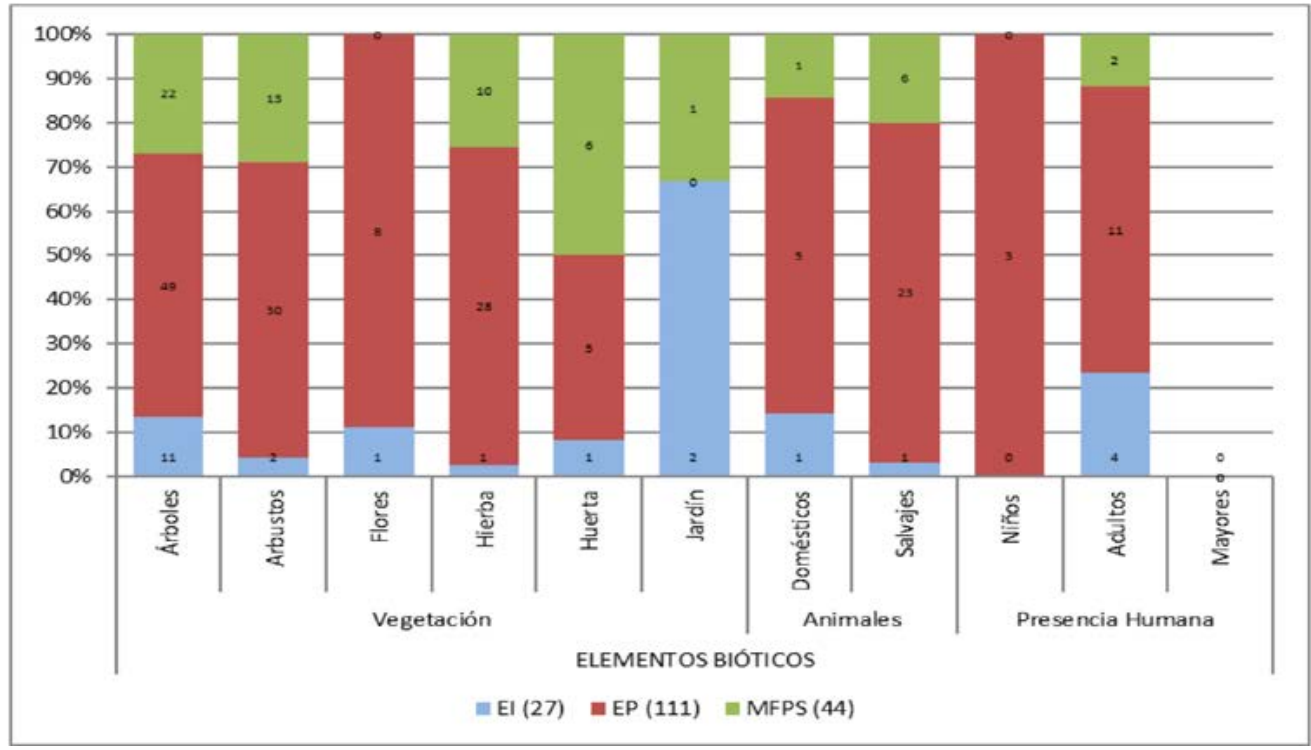

FIguRA 9. Distribución de los elementos bióticos según subcategorías y titulaciones. Fuente: elaboración propia.

En cuanto a los elementos antrópicos dibujados (Figura 10) por los alumnos, en la categoría de edificaciones se repiten los monumentos (34), edificios aislados (31) y casas rurales y pueblos (21). Las vías de comunicación que más aparecen son los caminos (27) en mayor medida que las calles (19). En los medios de transporte, llama la atención la presencia de barcos (28) ligada al elemento playa y mar que tanto se repetía. En el apartado de utensilios humanos, han dibujado mobiliario urbano diverso: farolas, chiringuito, toallas, bancos, sombrilla, papelera, plataforma de acceso a playa, material deportivo náutico (piragua, moto acuática, flotadores), casi todo ello relacionado con un paisaje de costa.

Las diferencias por titulaciones muestran que, en el apartado de edificaciones, los alumnos de GEI señalan parques, mientras que los de MFPS representan más los pueblos. El faro es una edificación que sólo señalan los estudiantes de MFPS y GEP. Finalmente, destaca que los edificios educativos sólo son representados por los GEP. 


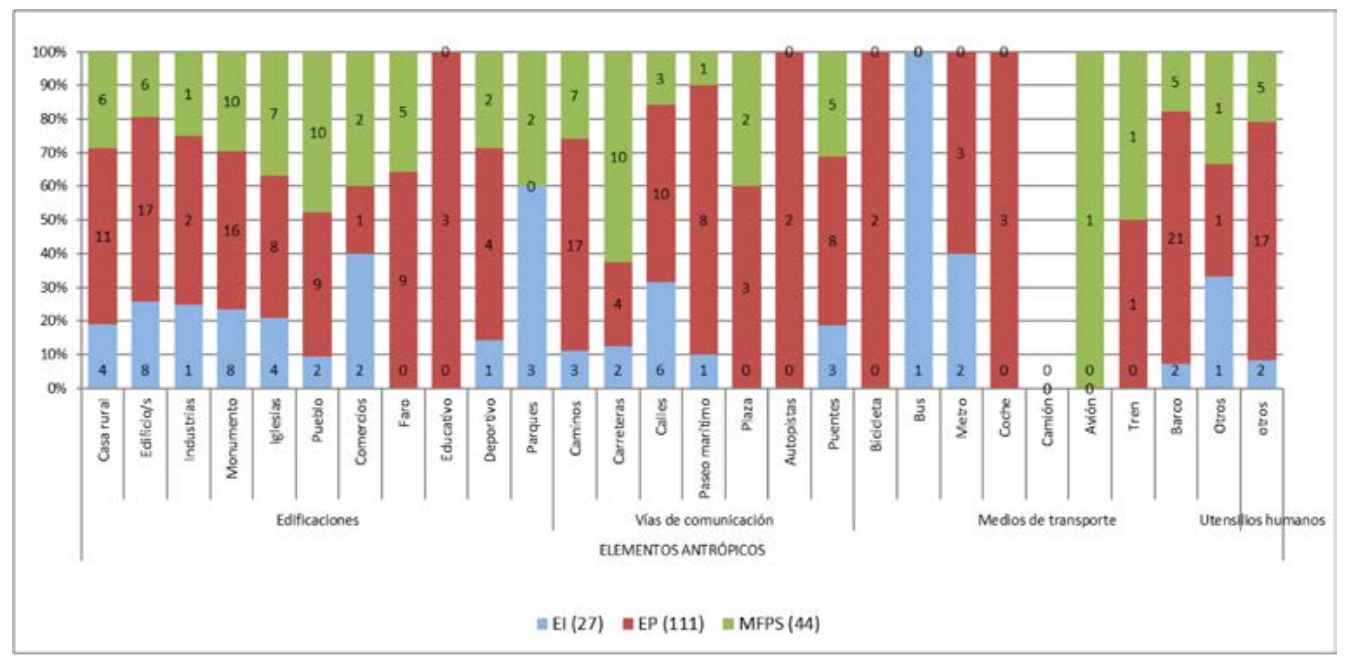

FIGURA 10. Distribución de los elementos antrópicos según subcategorías y titulaciones. Fuente: elaboración propia.

\subsection{Paisajes descritos por los alumnos}

Los alumnos que han descrito el paisaje han sido 180 de los 182 , esto es, el 98,9\%. Destaca la variedad entre las diferentes descripciones. En un nivel formal, el límite señalado en la longitud del texto era de medio folio. Los textos de los alumnos oscilaban entre las 6 y las 226 palabras, con un promedio de 77 palabras por descripción. Sí parece que hay variación entre las titulaciones, los estudiantes de GEI utilizan 55,6 palabras por descripción, los de GEP sube a 72,6 las palabras; finalmente, los alumnos de MFPS utilizan como término medio 106 palabras por descripción. La cita de topónimos concretos por los estudiantes se sitúa en los 2,9 por descripción, y varía muy poco entre las distintas titulaciones, 3,5 en GEI, 2,6 en GEP y 3 en MFPS.

En cuanto a los contenidos, apenas hay descripción del paisaje desde un enfoque global y sistémico, pues los datos muestran, si se atiende a la clasificación de tipos de paisaje de Liceras (2003), que no explicitan si se trata de un paisaje natural, rural o urbano, salvo en tres casos $(1,65 \%)$; aunque de forma implícita se pueden extraer de las descripciones de los distintos elementos que componen los paisajes. También se puede ver (Tabla 7) que apenas el $20 \%$ de los estudiantes identifican el tipo de paisaje siguiendo alguno de los criterios de la clasificación de Crespo (2017). Por sus elementos dominantes, aparecen de forma explícita los paisajes naturales (2), 
los rurales (1) y urbanos (1). En cuanto al clima, se cita el paisaje mediterráneo (1); según el relieve señalan el paisaje de montaña (2) y el paisaje de costa (2). Por la litología, aparecen 3 paisajes volcánicos, de manera implícita aparece el paisaje granítico (1) y el calcáreo (2). Por su funcionalidad sólo se explicita en una ocasión el paisaje "agrícola", aunque es cierto que diez alumnos enfocan su descripción al paisaje agrícola o pesquero que eligen, destacando y concretando muchos de sus elementos, por este motivo se han contabilizado. También se han tenido en cuenta aquellas descripciones en las que los estudiantes subrayaban el estado del paisaje (degradado -masificado-, conservado o protegido), aunque la perspectiva adoptada no fuera la fundamental.

Finalmente, los estudiantes no contemplan en sus descripciones la adscripción de un paisaje a su región biogeográfica, o la génesis de su relieve (en dos casos hablan de la evolución geológica, pero sin concretar); tampoco hacen alusión a la dinámica de ese paisaje. Como veremos más adelante, sí se refieren a elementos singulares de los paisajes, históricos o culturales, pero no hablan de ese tipo de paisajes; sólo en dos casos hablan del valor del patrimonio cultural del paisaje.

En general, se aprecia que los alumnos del MFPS tienden más a identificar tipos de paisajes siguiendo algunos de los criterios que los alumnos de GEI-GEP.

La distribución global de las categorías de los elementos del paisaje descrito es distinta pero coherente con la dibujada (Figura 11). Los elementos abióticos son los que tienen mayor peso (51\%), con mucha distancia respecto a los primeros; los elementos bióticos (25\%) y los antrópicos (24\%) están igualados. En números absolutos se han identificado 654 elementos descritos por los alumnos en todas las categorías. Según las titulaciones, en GEI pesan menos los elementos abióticos (45\%) y aumenta en unos diez puntos los antrópicos. Los estudiantes de GEP y MFPS están más igualados.

Se encuentran muchas dificultades para aplicar las mismas subcategorías de dibujo a la descripción, sobre todo porque los estudiantes utilizan un vocabulario más variado para nombrar los elementos más concretos del paisaje. Así pues, para analizar estas descripciones de los elementos del paisaje, se utilizan sólo las once grandes categorías trabajadas. 


\begin{tabular}{|c|c|c|c|c|c|}
\hline CRITERIO CLASIFICACION & TIPOLOGÍA & EI & EP & MFPS & Total \\
\hline \multirow{4}{*}{ Elementos dominantes } & Naturales & 0 & 1 & 1 & 2 \\
\hline & Rurales & 0 & 0 & 1 & 1 \\
\hline & Urbanos & 0 & 1 & 0 & 1 \\
\hline & Industriales & 0 & 0 & 0 & 0 \\
\hline \multirow{4}{*}{ Clima } & Mediterráneo & 0 & 1 & 0 & 1 \\
\hline & Atlántico & 0 & 0 & 0 & 0 \\
\hline & \begin{tabular}{|l|} 
Subtropical \\
\end{tabular} & 0 & 0 & 0 & 0 \\
\hline & De montaña & 0 & 0 & 0 & 0 \\
\hline \multirow{4}{*}{ Relieve } & De montaña & 0 & 1 & 1 & 2 \\
\hline & De valle & 0 & 0 & 0 & 0 \\
\hline & De llanura & 0 & 0 & 0 & 0 \\
\hline & De costa & 0 & 2 & 0 & 2 \\
\hline \multirow{4}{*}{ Litología } & Calizos & 0 & 0 & 0 & 0 \\
\hline & Graníticos & 0 & 0 & 0 & 0 \\
\hline & Arcilloso & 0 & 0 & 0 & 0 \\
\hline & Volcánico & 0 & 2 & 1 & 3 \\
\hline \multirow{3}{*}{ Biogeografía } & Mediterráneos & 0 & 0 & 0 & 0 \\
\hline & Eurosiberianos & 0 & 0 & 0 & 0 \\
\hline & Macaronésicos & 0 & 0 & 0 & 0 \\
\hline \multirow{3}{*}{ Génes is de su relieve } & Paleozoicos & 0 & 0 & 0 & 0 \\
\hline & Mesozoicos & 0 & 0 & 0 & 0 \\
\hline & Cenozoicos & 0 & 0 & 0 & 0 \\
\hline \multirow{3}{*}{ Funcionalidad } & $\begin{array}{l}\text { Primarios (agrícola, } \\
\text { cultivos, pesquero...) }\end{array}$ & 2 & 4 & 5 & 11 \\
\hline & Secundarios & 0 & 0 & 0 & 0 \\
\hline & Terciarios & 0 & 0 & 0 & 0 \\
\hline \multirow{3}{*}{ Dinámica } & En regresión & 0 & 0 & 0 & 0 \\
\hline & En progresión & 0 & 0 & 0 & 0 \\
\hline & En equilibrio & 0 & 0 & 0 & 0 \\
\hline \multirow{3}{*}{ Estado } & Degradado (masificado) & 0 & 2 & 4 & 6 \\
\hline & Conservado & 0 & 2 & 2 & 4 \\
\hline & Protegido & 0 & 2 & 1 & 3 \\
\hline \multirow[t]{3}{*}{ Elementos singulares } & His tóricos, culturales & 0 & 0 & 0 & 0 \\
\hline & Total & 2 & 18 & 16 & 36 \\
\hline & $\begin{array}{l}\text { Proporción respecto al } \\
\text { número de estudiantes } \\
\text { de la titulación }(\%)\end{array}$ & 7,4 & 16,2 & 36,4 & 19,8 \\
\hline
\end{tabular}

TABla 7. Concepción de los paisajes por los estudiantes según la clasificación de Crespo (2017). Fuente: elaboración propia. 


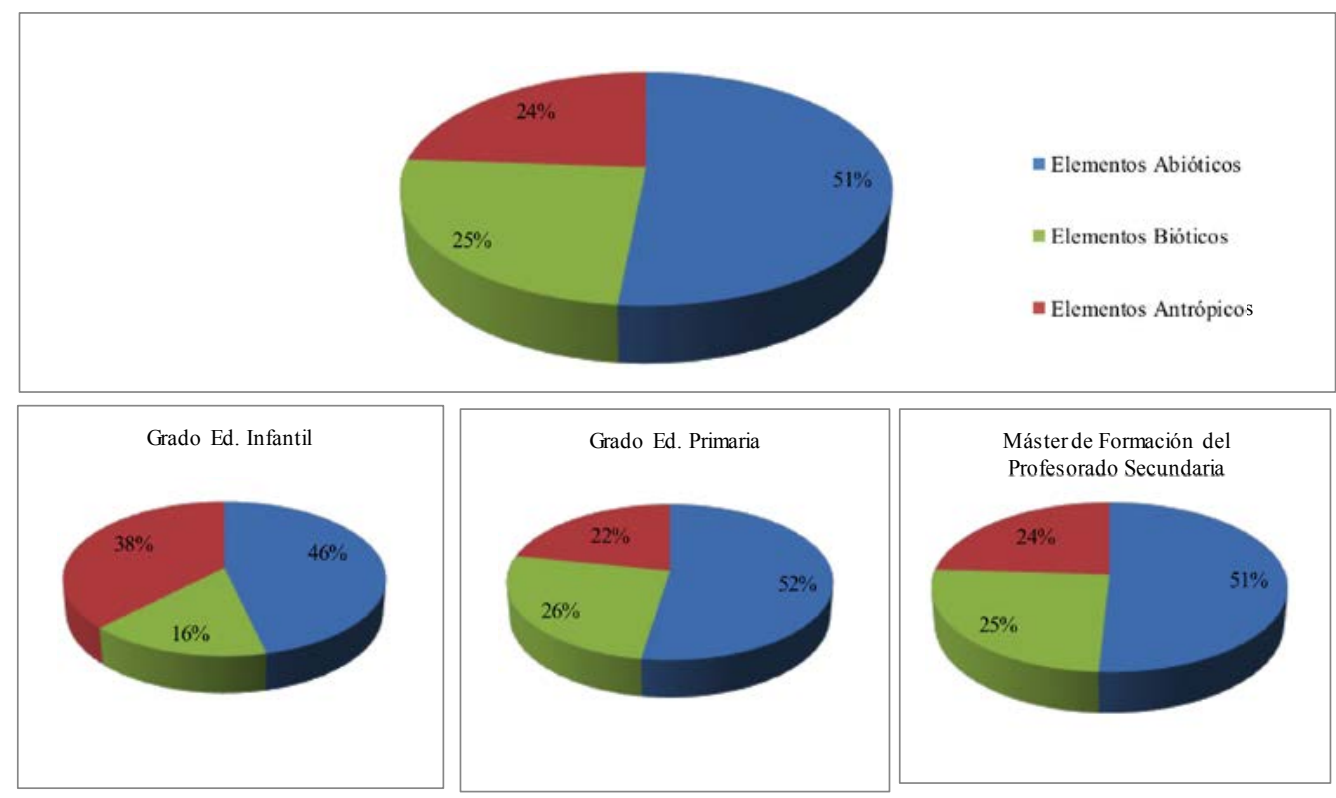

FIgURA 11. Distribución de los elementos abióticos, bióticos y antrópicos del paisaje descrito (\%). Fuente: elaboración propia.

\subsubsection{Descripción de elementos abióticos}

Los elementos abióticos de las categorías del paisaje que utilizan con más frecuencia los estudiantes en sus descripciones son los que aparecen en la Figura 12 (se cuentan también por sujetos). Vemos que incluyen elementos del relieve 131 alumnos, de la hidrografía 108 y de la atmósfera 87. Sólo 11 alumnos hacen referencia a algún astro.

Las formas o partes del tipo de relieve predominante en las descripciones serían: montañas (61), sierra (8), valles (7), cima (3), pico (3), ladera (6), desfiladeros (1), cueva (1), incluso aparecen los mogotes kársticos (1). Se cita la Meseta (3), el páramo (1), el otero (1) y la nava (1). Algunos elementos destacan entre las formas de relieve litoral: playa (48), islas (16), costa (13), acantilado (9), llanura (7), cala (7), cabo, peñón, marisma, duna y bahía (2), islote, archipiélago y barranco (1). Para el relieve volcánico o volcanes (8), concretan: lava (2), erupción (2), cráter (2). Los procesos de formación que se refieren a este tipo de elementos aparecen contadas veces: erosión (2), formación geológica (1), sismos, avalanchas y terremotos (1). 


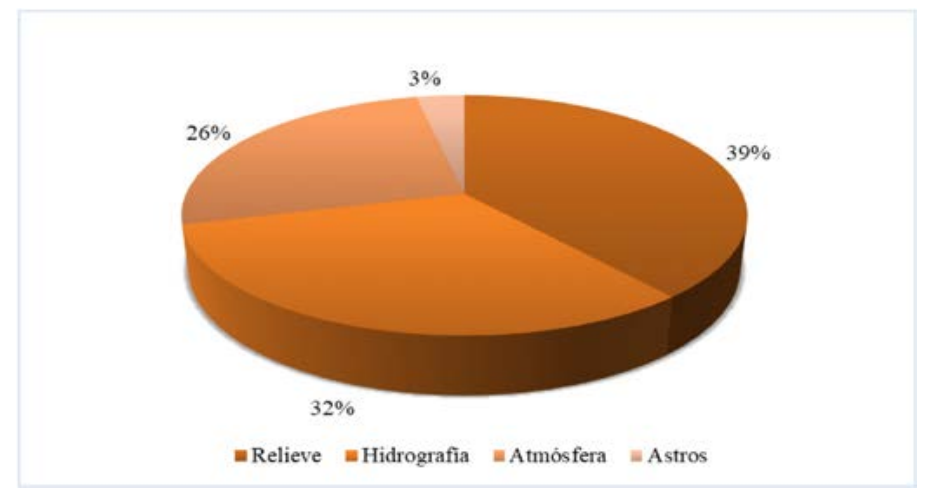

FIGURA 12. Elementos abióticos que aparecen en las descripciones. Fuente: elaboración propia.

En cuanto a los elementos de hidrografía, destacan los ríos (42), y hablan de su nacimiento o fuentes (3), de su cuenca o vertiente, de su mayor o menor caudal (3). También se refieren a los mares (30) y océanos (5), lagos y lagunas (14), cascadas (3), arroyo (2), charca (1) y finalmente, la nieve (12) con la denominación concreta de nevero (1). El elemento que más señalan del mar son las aguas (15) calificándolas de cálidas o frías, cristalinas o contaminadas según el caso, y las olas (6).

Respecto a los elementos de la atmósfera, en sus descripciones, los estudiantes utilizan términos como: clima (43), temperaturas (25), calor o caluroso (11), frío o fresco (7), templado (4), oscilación térmica (2), precipitaciones (7), lluvia (11), niebla (1), humedad (6), seco (6), árido (3), desértico (1), viento (3), brisa (1). Los tipos de clima que se citan de forma recurrente son: clima oceánico (3) y "cantábrico" (1) asociado a lluvias y a humedad; clima mediterráneo de interior (3) asociado a fuertes contrastes de temperaturas, y clima mediterráneo de costa (2) asociado a temperaturas altas, sequía y gota fría. El clima tropical aparece citado (4) y se asocia a paisajes como Singapur, Lanzarote, Granada o Cádiz.

Finalmente, las contadas ocasiones en las que se cita al sol (9) o estrellas (2), se hace en función de las puestas de sol, contemplación de amaneceres, atardeceres, o de noches estrelladas.

En la Figura 13 se exponen los datos de descripciones de elementos abióticos según categorías y titulación. Los estudiantes de MFPS son los que más describen, y con diferencia respecto de GEP que les siguen, los elementos de las categorías relieve e hidrografía; en ambos casos más de la mitad de los alumnos describen elementos de estas categorías. Los elementos de la categoría atmósfera son más trabajados por los alumnos de GEP, aunque en este caso la diferencia entre ambos grupos es menor. Los de 
MFPS vuelven a superar a los de GEP en sus descripciones de la categoría astros. Llama la atención, por el contrario, que los estudiantes de GEI que hacen descripciones en estas categorías no supera la mitad, incluso no hacen referencia a los astros.

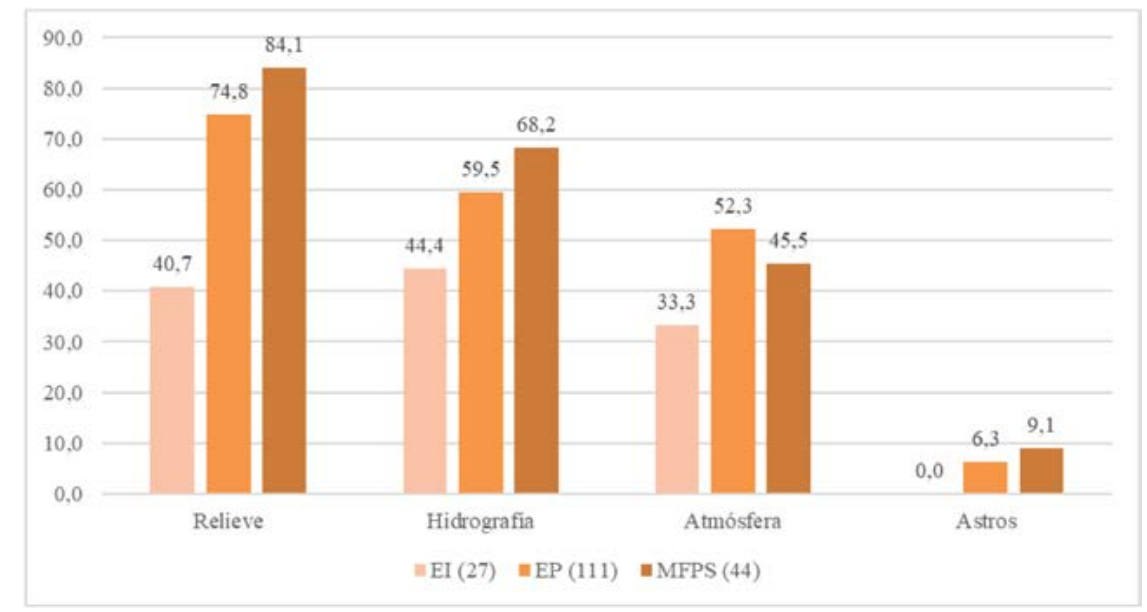

FIGURA 13. Elementos abióticos que aparecen en las descripciones según titulación de los estudiantes. Fuente: elaboración propia.

\subsubsection{Descripción de elementos bióticos}

En la categoría de los elementos bióticos, destaca la subcategoría vegetación con la aportación de dos tercios de los alumnos. Los animales en las descripciones suponen poco más de un tercio, y la presencia humana es pequeña (Figura 14).

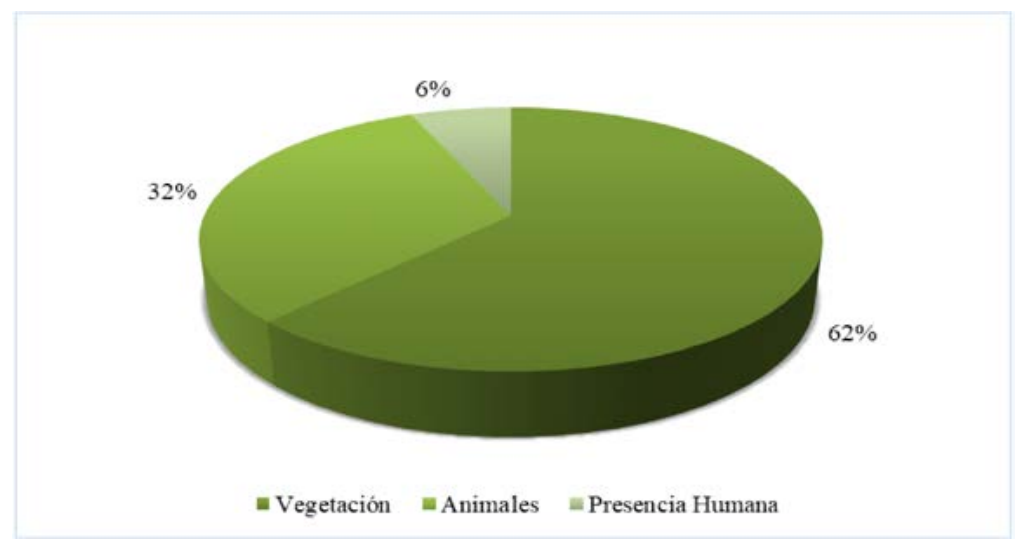

FiguRA 14. Elementos abióticos que aparecen en las descripciones. Fuente: elaboración propia. 
En la categoría de la vegetación, destacan la presencia de árboles (25) o arboleda (3), y entre ellos se citan el pino (9) unido a los que se citan a continuación; la encina (7) y el alcornoque (3) asociados, el eucalipto (3) y el roble (2) asociados también. El chopo (1) aparece como vegetación de ribera de río y la palmera (7) se une con vegetación de montaña baja, naranjos o cultivo de arroz. Los arbustos (6), matorral (1), plantas aromáticas (1) tienen menor presencia. La suma de huertas, campos y cultivos (20), se concretan en trigo, maíz y girasol (3), naranjal (3) y limoneros (1), campos de arroz (2) y melones (1); finalmente viñedos y olivos (2).

En la categoría de los animales, se refieren a ellos de forma genérica como fauna o especies, señalando su presencia y variedad (19); en el apartado de los salvajes, algunas especies más exóticas y concretando las especies "de paso" (ballenas, delfines, pájaros) para referirse a las actividades de avistamiento de aves (2) o a la migración (1). También aparecen "especies en peligro de extinción": lince, gato montés y zorro (1), citan otros relacionados con la actividad cinegética: ciervos (4), conejos (3) y liebres (2). En el apartado de los domésticos hacen referencia a la ganadería fundamentalmente, con el genérico ganado (3) o rebaño (2) de cabritillas (1), ovejas (2) y merina (1). Destaca la aparición de la vaca en seis descripciones, normalmente en paisajes del norte de la península.

Conviene señalar que varios alumnos comentaron las figuras de protección de algunos de los espacios que seleccionaron y lo justificaron por la riqueza y variedad de especies de flora y fauna. En concreto: el PN Teide, Parque Natural de Corralejo y Reserva Natural Dunas de Maspalomas en las Islas Canarias (1 GEP y 2 MFPS), Parque Regional de Calblanque (1 MFPS y 1 GEP), PN de Picos de Europa (1 GEP). Finalmente, el PN Ciénaga de Zapata, (Matanzas, Cuba), Murchison Falls National Park (NO Uganda), Byron Bay (Australia) y el PN Islas del Atlántico (en los cuatro casos estudiantes de MFPS). Dos alumnos de GEI citan el PN Teide y PN de Timanfaya sin comentar la figura de protección y 1 alumno de GEP hace lo mismo respecto del PN Picos de Europa.

La presencia humana en las descripciones es escasa (10), sin embargo, aparecen correctamente calificadas. Se refieren a ellas en términos de despoblamiento, baja natalidad, población escasa o envejecida.

Conviene destacar que, también los elementos bióticos (Figura 15) son descritos por los alumnos del MFPS en mayor medida que el resto de las titulaciones, tanto la vegetación como los animales; sólo la presencia humana aparece más en los estudiantes de GEP. 


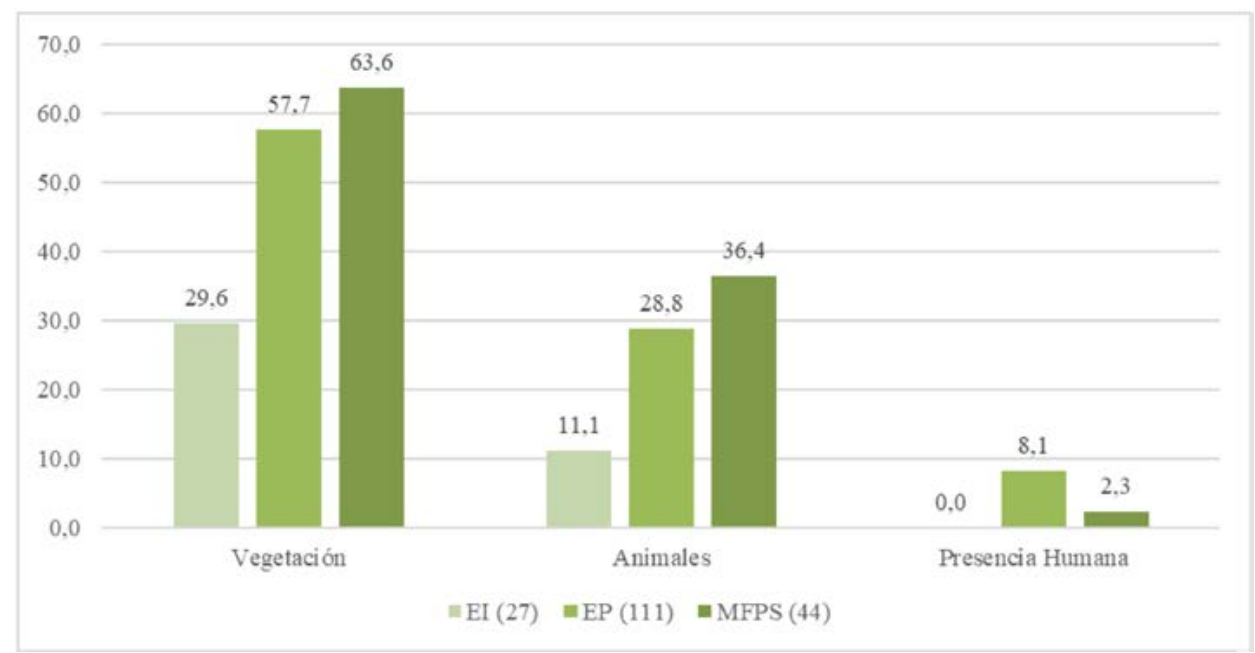

FIGURA 15. Elementos bióticos que aparecen en las descripciones según titulación de los estudiantes. Fuente: elaboración propia.

\subsubsection{Descripción de elementos antrópicos}

En la Figura 16 se puede ver cómo, en esta categoría, son las edificaciones las descritas por los estudiantes de forma mayoritaria (68\%), las vías de comunicación no llegan a la cuarta parte $(24 \%)$, mientras que los medios de transporte y otros utensilios aparecen citados en pocas ocasiones, $7 \%$ y $1 \%$ respectivamente.

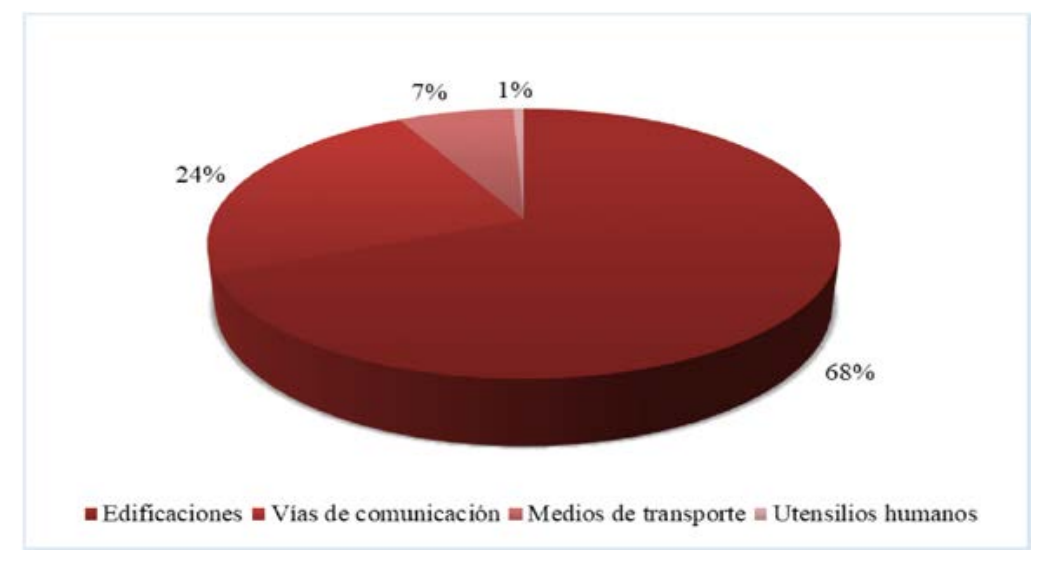

FIGURA 16. Elementos antrópicos que aparecen en las descripciones. Fuente: elaboración propia. 
En la categoría edificaciones, se habla de pueblos (25), ciudades (10), barrio (9), aldea (2) y de urbanizaciones (3). También hablan de casa (1) y edificios (8). Se enfoca también la ciudad destacando su desarrollo: el casco antiguo o histórico (6) y zona de ensanche o nueva (2). Algunos destacan de los edificios su funcionalidad, así se citan comercios, tiendas, supermercados o "milla de oro" (7), restaurantes (6), bares (3), deportivo (1), parque (6), puertos (3) y faro (6). Finalmente, se encuentran descritos o citados muchos edificios que se incluyen en el patrimonio cultural (concepto que se cita en dos ocasiones), y son: el genérico monumento (11), iglesia (16) con sus variantes: templo, basílica, catedral, monasterio, convento y capilla. Se encuentra también mirador (6), muralla (2), plaza (3), museos (5), palacio o castillo (3), restos arqueológicos (1), fuentes (1) y estanques (1); todos ellos aparecen ligados a las actividades de ocio y descanso que motivan sus visitas.

En el apartado de comunicaciones y transportes, citan las carreteras (4), autopistas (2), calles (2), canales (2), puentes (3), paseos marítimos (3) y senderos de montaña (2) dirigidos más hacia el ocio y el deporte que a la comunicación.

Finalmente, se ha de destacar que, los elem entos antrópicos (Figura 17) son descritos por los alumnos del GEI más que el resto de las titulaciones en el apartado de edificaciones (67\%) seguidos por los de MFPS (64\%); y en medios de transporte con apenas un punto de diferencia entre ambos. En la categoría de vías de comunicación los alumnos de MFPS destacan sobre el resto (27\%).

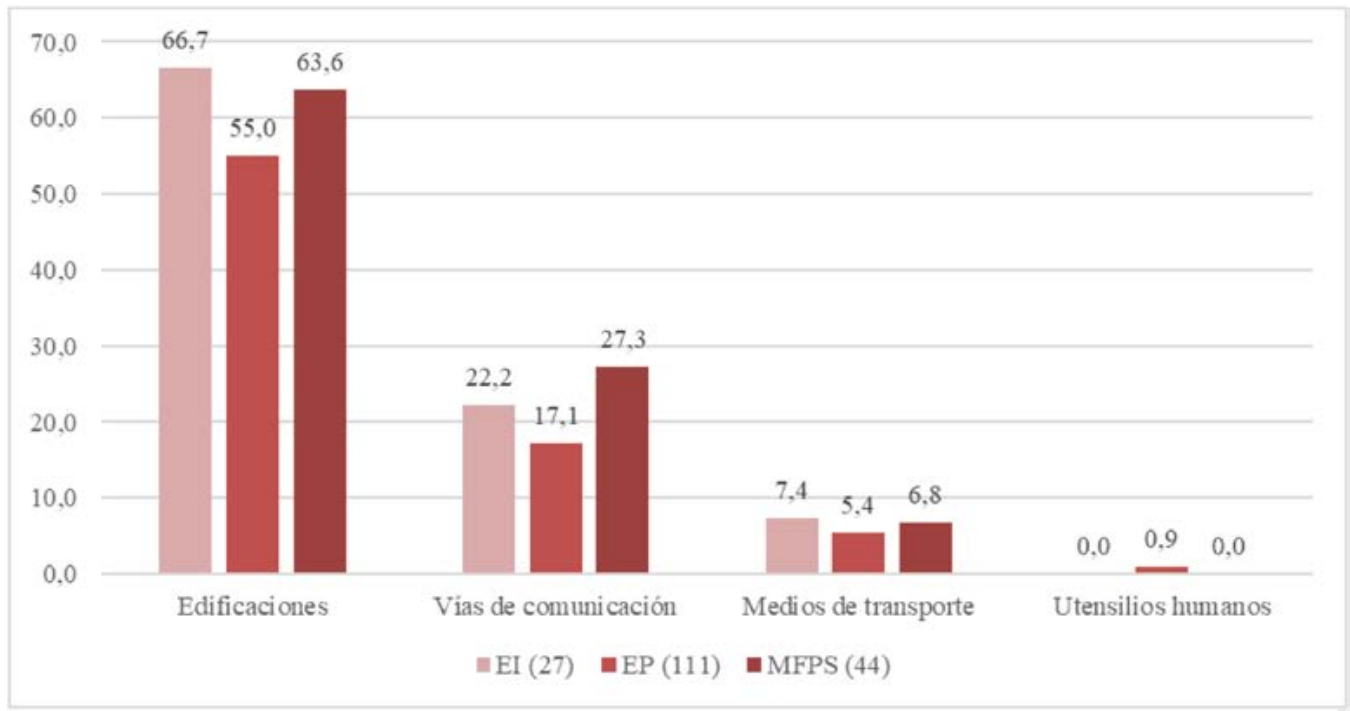

FIGURA 17. Elementos antrópicos que aparecen en las descripciones según titulación de los estudiantes. Fuente: elaboración propia. 
Para finalizar, se han clasificado las estrategias descriptivas escritas utilizadas por los estudiantes, futuros docentes (Figura 18). Se comprueba que el 65\% identifican y sitúan los elementos del paisaje. Poco más del $38 \%$ ordena dichos elementos organizándolos con una estructura razonada. El $43 \%$ de los alumnos relaciona los elementos de las tres categorías propuestas. Estos resultados se explican por tratarse de una prueba inicial y abierta, sin señalar previamente a los alumnos ningún modelo a seguir.

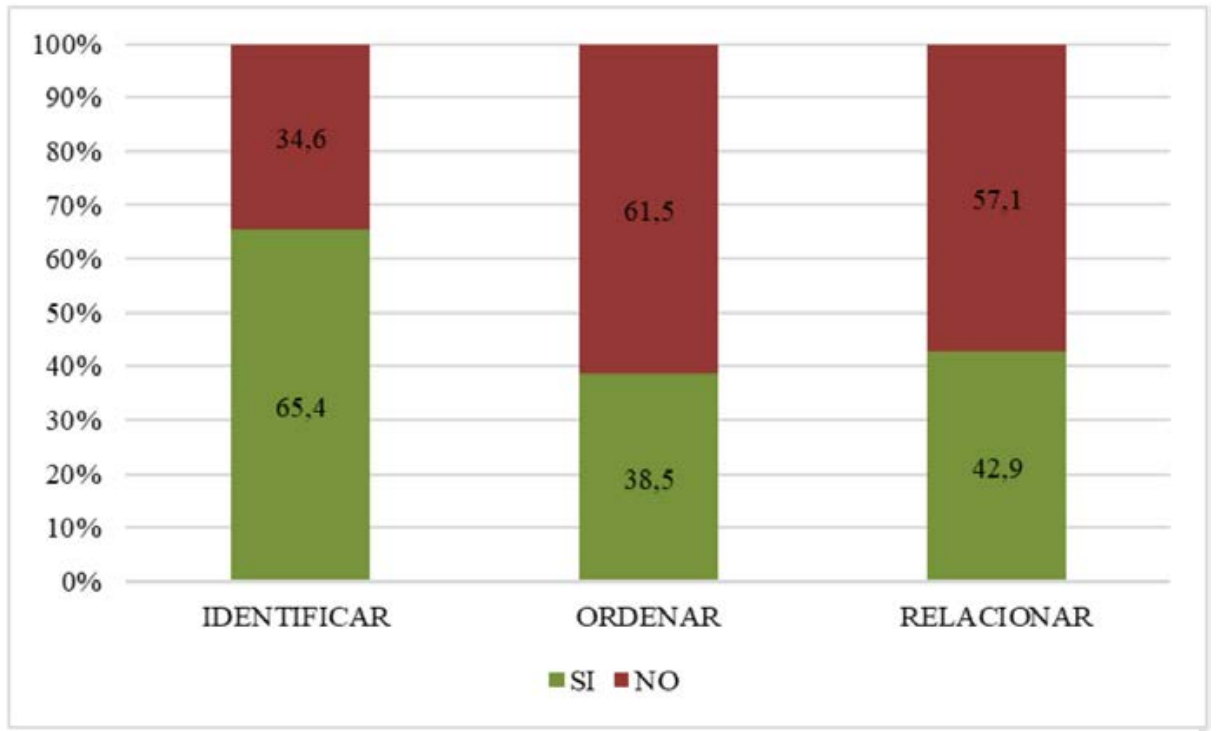

FIgURA 18. Clasificación de las estrategias descriptivas escritas utilizadas por los alumnos. Fuente: elaboración propia sobre modelo de Mateo (2016)

Los resultados por titulaciones revelan diferencias (Tabla 8). Los estudiantes del GEI presentan unos resultados poco positivos en las tres destrezas, si bien es cierto que la muestra es pequeña y no resulta significativa. En el caso de los estudiantes de MFPS sucede al contrario, más de dos tercios de los alumnos sí trabajan las tres estrategias de descripción escrita, aunque aquí la muestra es mayor, todavía requeriría completarla. En GEP, con más de 111 estudiantes, sí se pueden aportar datos significativos. Se observan en este grupo porcentajes similares a los de MFPS, más de dos tercios de los alumnos sí utilizan estas destrezas en la descripción escrita de sus paisajes. Estos resultados pueden ayudar a elaborar propuestas de mejora en la adquisión de dichas competencias. 


\begin{tabular}{ccccc}
\hline & & Identificar & Ordenar & Relacionar \\
\hline GEI & $\mathrm{Si}$ & 44,4 & 22,2 & 22,2 \\
$(27)$ & $\mathrm{No}$ & 55,6 & 77,8 & 77,8 \\
GEP & $\mathrm{Si}$ & 64,9 & 66,7 & 61,3 \\
$(111)$ & $\mathrm{No}$ & 35,1 & 33,3 & 38,7 \\
MFPS & $\mathrm{Si}$ & 79,5 & 61,4 & 65,9 \\
$(44)$ & $\mathrm{No}$ & 20,5 & 38,6 & 34,1 \\
\hline
\end{tabular}

TABLA 8. Clasificación de las estrategias descriptivas escritas utilizadas por los estudiantes según titulaciones. Fuente: elaboración propia sobre modelo de Mateo (2016)

\subsection{Coherencia entre lo que dibujan y describen los alumnos}

Se trata de ver si las distintas categorías de elementos dibujados aparecen en las descripciones realizadas por los alumnos. Se han utilizado dos métodos. El primero, más sencillo, es asignar a cada uno de los registros si se observa ese grado de coherencia en función de los elementos citados y dibujados. Así pues, se ve (Figura 19) que tanto en los estudiantes de grado (sin diferenciar los de GEI y GEP dado que los valores eran similares), como en los de master hay coherencia entre sus dibujos y sus descripciones. Ahora bien, llama la atención que el porcentaje de coherencia del 56\% en los estudiantes de grado aumente al $80 \%$ en los alumnos de máster.

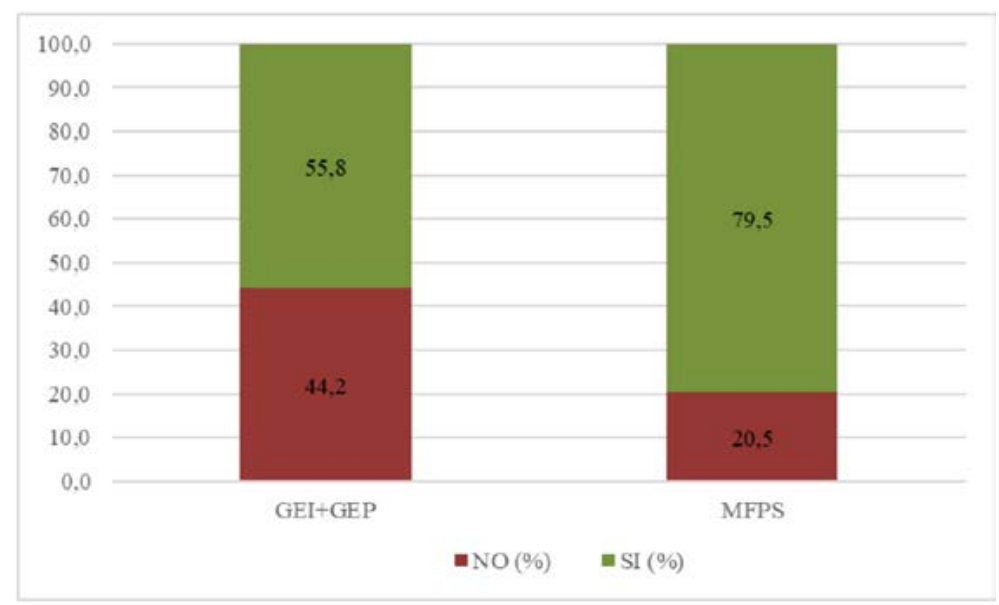

FIGURA 19. Grado de coherencia entre dibujo y descripción según titulación.

Fuente: elaboración propia. 
En un segundo momento, y para complementar lo anterior, se confrontan los datos (porcentajes sobre el total de cada titulación) de los dibujos y las descripciones de las categorías fundamentales por titulaciones que se vieron en apartados anteriores. Se ha elaborado la Tabla 9 para mostrar los resultados. Los porcentajes de los dibujos y las descripciones de elementos abióticos y bióticos son muy similares en alumnos de master con muy poca variación (y esta es positiva para la descripción, esto es, describen más que dibujan). No pasa igual con los alumnos de grado, en los elementos abióticos hay mucha diferencia entre lo dibujado y lo descrito; además, en el caso de los abióticos se describe más de lo que se dibuja, pero en los bióticos se dibuja más de lo que se escribe). Esto indica, en general, la falta de vocabulario para trabajar estos elementos bióticos. Finalmente, se ve cómo en los elementos antrópicos se distancia más lo dibujado de lo descrito, a favor del dibujo.
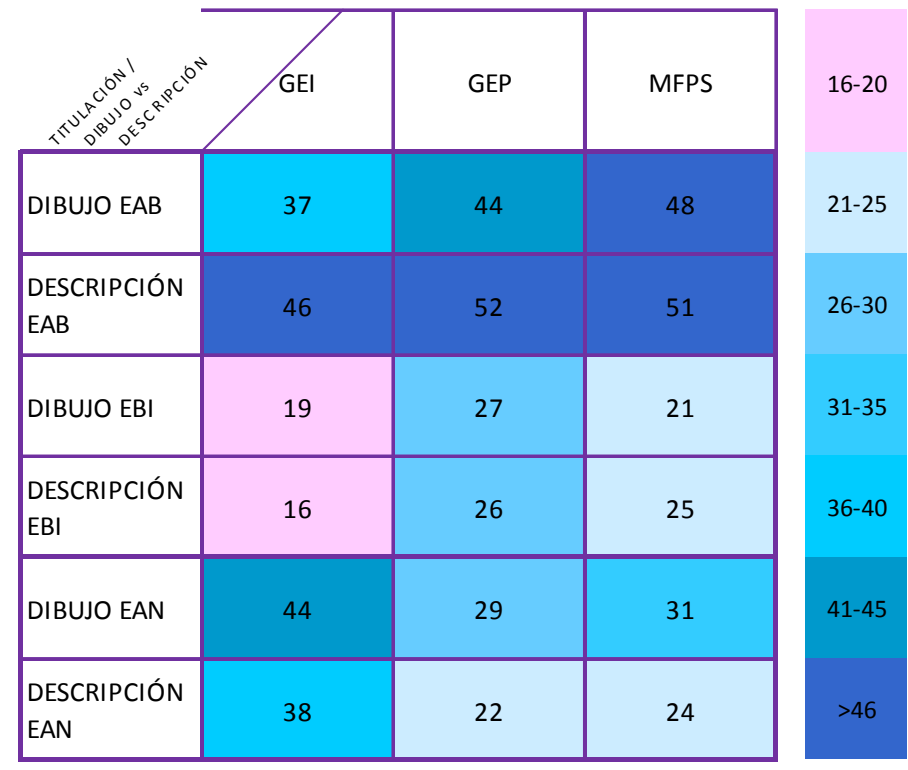

LEYENDA

TABLA 9. Grado de coherencia entre dibujo y descripción según titulación y categoría de elementos. Fuente: elaboración propia.

\section{REFLEXIONES FINALES. LIMITACIONES Y PROPUESTA DE MEJORA}

En primer lugar, se observa que el perfil del estudiante que se ha estudiado es originario de España (90\%), de paisajes de interior (84\%) y nacidos en entornos urbanos (95\%). Declaran una experiencia viajera aceptable ( 7,8 viajes/estudiante), tanto en el interior de España $(4,1)$ como al exterior $(3,8)$. Sin embargo, los paisajes que prefieren 
son distintos al de nacimiento (72\%), localizados en el ámbito nacional (74\%), en espacios costeros (54\%) y en entornos rurales (64\%).

Las concepciones plasmadas en los dibujos y descripciones de los paisajes preferidos por los alumnos muestran que los elementos bióticos y abióticos suman un $75 \%$ de dibujos y descripciones, sólo un $24 \%$ corresponden a elementos antrópicos.

Todo esto parece evidenciar que las concepciones sobre el paisaje de los alumnos que proceden en un $95 \%$ de entornos urbanos lo identifican como un espacio poco intervenido y definido por sus valores naturales. Esta primera conclusión refuerza la idea de que la sociedad urbana actual identifica la idea de paisaje con los paisajes naturales (Gómez, 1996).

En segundo lugar, pocos alumnos han mostrado una concepción del paisaje global y sistemática, pues sólo entre el 1,6\% (modelo de Liceras, 2003) y el 20\% (modelo Crespo, 2017) citan alguna de las tipologías concretas de paisaje y las describen. Como se apuntó anteriormente, los estudiantes de MFPS son los que más tienden más a identificar tipos de paisajes siguiendo algunos de los criterios que los de GEI-GEP. En este sentido, es necesario replantearse y/o mejorar la inclusión de contenidos curriculares enfocados desde la didáctica del paisaje en la enseñanza obligatoria.

En tercer lugar, se pueden mejorar las estrategias descriptivas escritas de los estudiantes en su formación inicial, sobre todo las relativas a ordenar y relacionar, aunque se puede matizar por titulaciones. Dado que las muestras de estudiantes de GEI y MFPS no son muy numerosas, es oportuno continuar con esta línea de investigación en próximos cursos para mejorar la consistencia de los resultados y proponer programas de escritura que mejoren las estrategias descriptivas en geografía.

En cuarto lugar, destaca la coherencia entre lo que dibujan y lo que describen. Tanto en dibujos como en descripciones, predominan las categorías de los elementos abióticos y, en este sentido, utilizan en sus descripciones un mayor número de términos geográficos, si bien es cierto que repiten algunos de forma muy genérica y son pocos estudiantes (sobre todo los de MPFS) los que introducen matices o concreciones. Los elementos bióticos, se dibujan menos y se describen igual o menos que los elementos antrópicos, y por supuesto, que los abióticos. En esta categoría de los bióticos, además, se constata que la mayoría destacan los elementos de vegetación, y apenas la fauna o la presencia humana. Se constata que los alumnos manejan un vocabulario muy reducido, y se refieren a la vegetación o a la fauna con términos genéricos y, en contadas ocasiones, concretan. Destacan las descripciones más detallada de los alumnos de GEP y MFPS. Los elementos antrópicos también se dibujan más y se describen menos. Esta proporción se debe, sobre todo, a aquellos elementos que se calificaban como "utensilios humanos" y que incluía mobiliario urbano diverso (p.13). En el caso de los elementos antrópicos, el 
vocabulario utilizado por los estudiantes, como hemos visto en los anteriores, es genérico y apenas aparecen conceptos geográficos en su descripción. Se puede concluir, por tanto, que es necesario trabajar el vocabulario geográfico específico tanto de geografía física como de geografía humana.

Para concluir, se ha visto que la didáctica del paisaje tiene una escasa tradición en cuanto al número de publicaciones registradas; por tanto, es una ciencia cuya investigación se encuentra en sus inicios. En este marco, se deben continuar estudios para mejorar la formación inicial del profesorado en la didáctica del paisaje que impliquen el desarrollo una concepción global y sistemática del paisaje, que enseñen el vocabulario geográfico para cada categoría de los elementos paisajísticos mediante el desarrollo las estrategias descriptivas; de manera que se capacite al alumno para tener una nueva mirada educada y educadora sobre el paisaje.

\section{BIBLIOGRAFÍA}

Adrados, T. (1998). Ideas previas y concepto de paisaje en alumnos de primaria. In J. R. Vera, E. M. Tonda \& M. J. Marrón (Coord.), Educación y geografía (pp. 145151). Alicante: Universidad de Alicante.

Crespo, J. M. (2018). La educación en paisaje en el Grado de Maestro de Educación

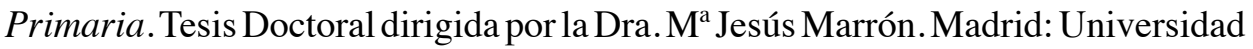
Complutense de Madrid. Retrieved from https://eprints.ucm.es/49394/

Gómez, A. (1996). El paisaje como elemento de referencia para el estudio de los diversos aspectos geográficos. Una aproximación a su significado curricular. In M. J. Marrón (Coord.) III Jornadas de Didáctica de la Geografía (pp. 195-215). Madrid: Universidad Complutense de Madrid

Iraola, I. (2007). Didáctica de la geografía humanística explorar el concepto de lugar en la ciudad postindustrial. Mostrar la acción educativa desde la narración del profesor. Tesis Doctoral. Leioa: Universidad del País Vasco.

Iraola, I. (2019). "Mirenen baserria": presente y futuro del caserío: una mirada desde la educación secundaria. Iber, 96, 26-35.

Liceras, A. (1996). La observación en el estudio del paisaje., In M. J. Marrón (Coord.) III Jornadas de Didáctica de la Geografía (pp. 295-302). Madrid: Universidad Complutense de Madrid.

Liceras, A. (2003). Observar e interpretar el paisaje: estrategias didácticas. Granada: Grupo Editorial Universitario.

Marrón, M. J. (1996). Introducción. In M. J. Marrón (Coord.) III Jornadas de Didáctica de la Geografía (pp. 5-7). Madrid: Universidad Complutense de Madrid. 
Martínez, R. \& Tonda, E. M. (2014). Nuevas perspectivas conceptuales y metodológicas para la educación geográfica. Córdoba: Universidad de Córdoba y Asociación de Geógrafos Españoles.

Mateo, M. T. (2016). Análisis del tratamiento de la descripción escrita en libros de texto de $1^{\circ}$ y de $3^{\circ}$ de educación secundaria obligatoria, en el bloque temático de Geografía, y su proyección en la formación del profesorado. Tesis Doctoral dirigida por el Dr. Teodoro Álvarez Angulo. Madrid: Universidad Complutense de Madrid. . Retrieved from https://eprints.ucm.es/40400/1/T38103.pdf 


\section{Anexo 1.}

Descripción y dibujo de estudiante de educación primaria, 2019. Autor: MM

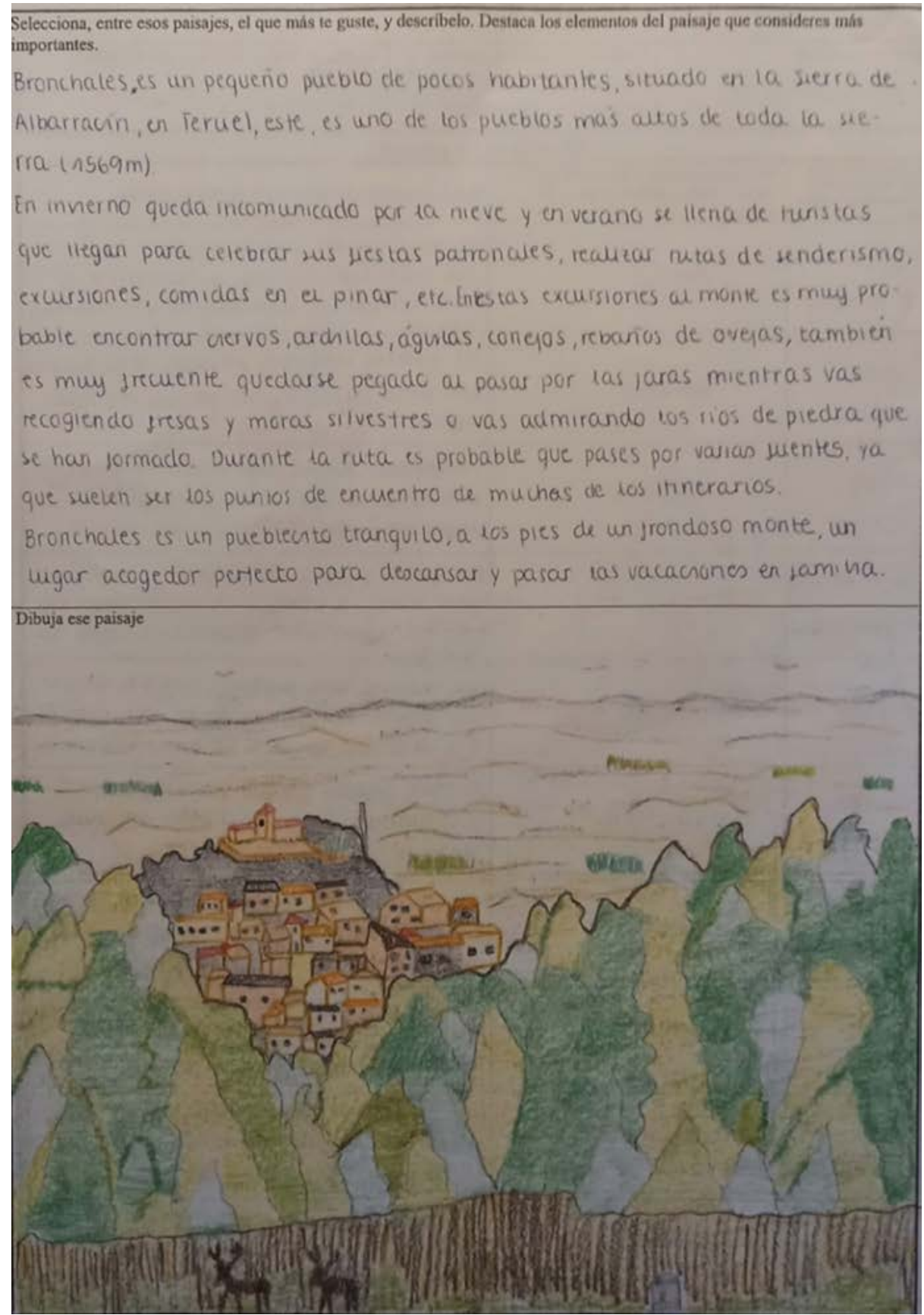




\section{María Rosa Mateo Girona}

\section{Anexo 2.}

Descripción y dibujo de estudiante de máster de formación de profesorado, 2019. Autor: MR

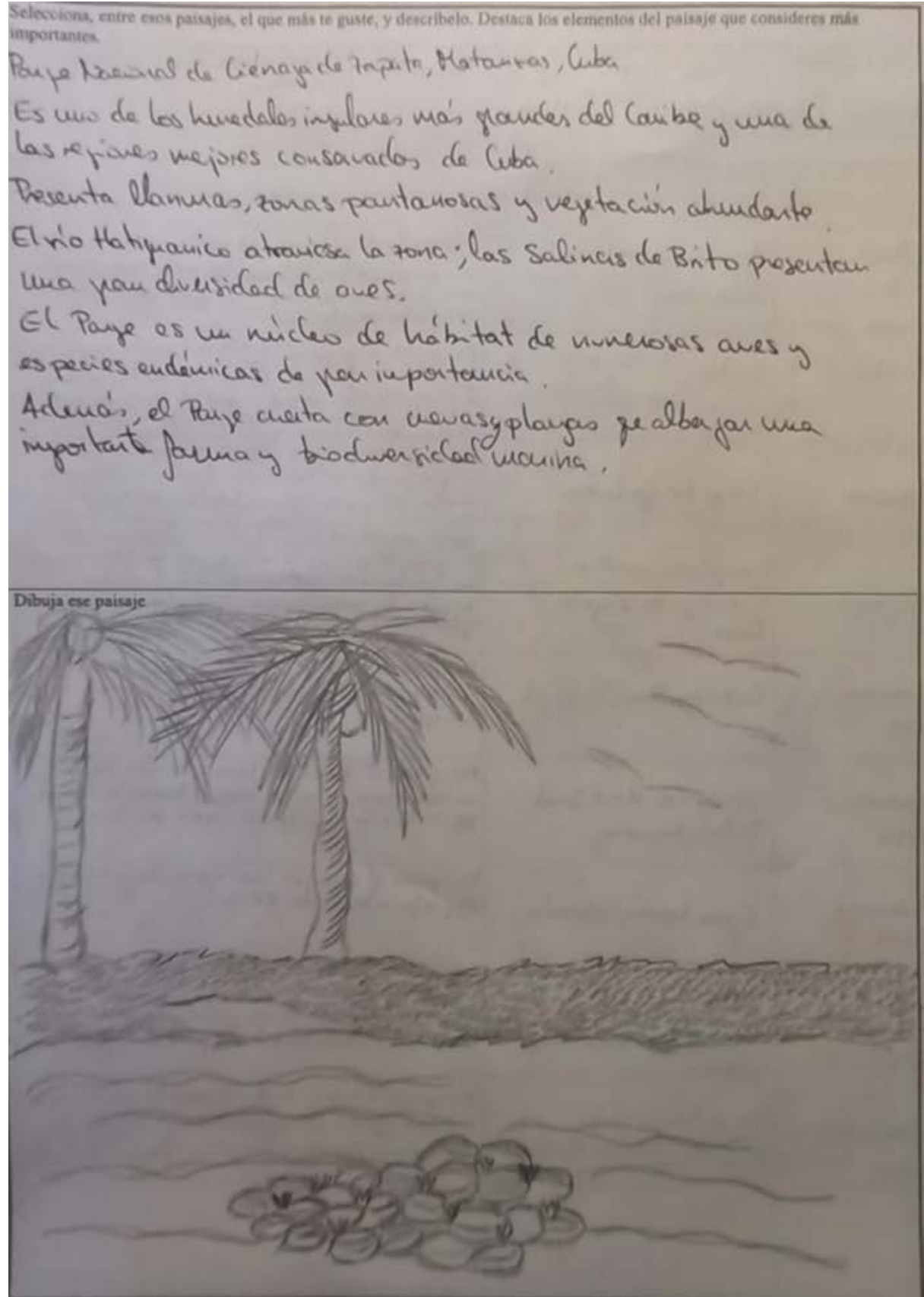

